Faculdade

de Ciências Econômicas UFRGS

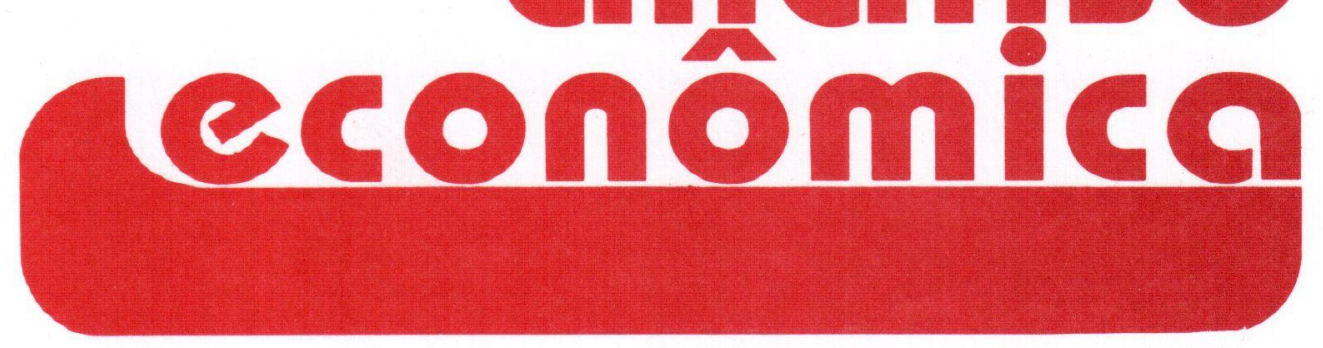

- A INTERNACIONALIzAÇÃo do Sistema FIINANCEIRO: 1990-1992

Lauro Lobo Burle

- GOVERNMENT INTERVENTION, INSTITUTIONAL FACTORS AND MARKET : AN ANALYSIS OF THE WAGE BARGAINING IN BRAZIL

Francisco Galrão Carneiro

- AINSTITUCIONALIZAÇÃO DA PREFERÊNCIA PELA LIQUIDEZ Albério Neves Filho

- PADRÕES MONETÁRIOS ALTERNATIVOS Fernando Carlos G. de Cerqueira Lima

- as contas nacionais e os custos AMBIENTAIS DA ATIVIDADE ECONÓMICA Charles C. Mueller

- LIVROS RECEBIDOS

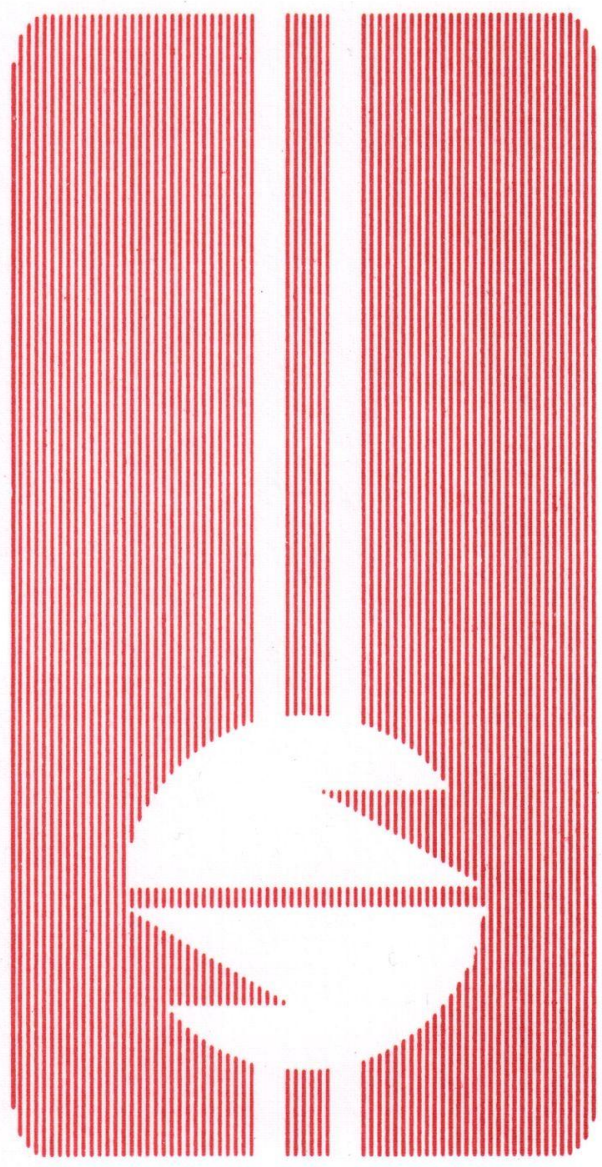


UNIVERSIDADE FEDERAL DO RIO GRANDE DO SUL Reitor Prof. Hélgio Henrique Casses Trindade

FACULDADE DE CIÊNCIAS ECONÔMICAS Diretor. Prof. Pedro Cézar Dutra Fonseca

CENTRO DE ESTUDOS E PEQUISAS ECONÔMICAS

Diretor. Prof. Paulo Alexandre Spohr

DEPARTAMENTO DE CIÉNCIAS ECONÔMICAS

Chefe: Prof. Achyles Barcelos da Costa

CURSO DE PÓS-GRADUAÇÃO EM ECONOMIA

Coordenador. Prof. Roberto Camps Moraes

CURSO DE PÓS-GRADUAÇĀO EM ECONOMIA RURAL

Coordenador. Prof. Atos Freitas Grawunder

CONSELHO EDITORIAL: Achyles Barcelos da Costa, Aray Miguel Feldens, Atos Freitas Grawunder, Carlos Augusto Crusius, Eugênio Lagemann, Fernando Ferrari Filho, Gentil Corazza, Juvir Luiz Mattuella, Marcelo Savino Portugal, Maria Imilda da Costa e Silva, Nali de Jesus de Souza, Nuno R. L. de Figueiredo Pinto, Otília Beatriz K. Carrion, Paulo Alexandre Spohr, Pedro Cezar Dutra Fonseca, Roberto Camps Moraes, Valter José Stülp, David Garlow (Wharton Econometrics Forecasts Association, E. U.A.), Edgar Augusto Lanzer (UFSC), Eleutério F. S Prado (USP), Fernando de Holanda Barbosa (FGV/RJ), Gustavo Franco (PUC/RJ), João Rogério Sanson (UFSC), Joaquim Pinto de Andrade (UnB), Juan H Moldau (USP), Werner Baer (Univ. de lllinois, E. U.A.).

COMISSÃO EDITORIAL: Atos Freitas Grawunder, Pedro Cezar Dutra Fonseca, Marcelo Savino Portugal, Roberto Camps Moraes.

EDITOR: Nali de Jesus de Souza

SECRETARIA: Cláudia Porto Silveira, Jeferson Luis Bittencourt e Vanete Ricachescki (revisão de textos).

FUNDADOR: Prof. Antônio Carlos Santos Rosa

Os materiais publicados na revista Análise Econômica são da exclusiva responsabilidade dos autores É permitida a reprodução total ou parcial dos trabalhos, desde que seja citada a fonte.

Aceita-se permuta com revistas congêneres. Aceitam-se, também, livros para divulgação, elaboração de resenhas e recensões.

Toda correspondência, material para publicaçăo (vide normas na terceira capa), assinaturas e permutas devem ser dirigidos ao seguinte destinatário:

PROF. NALI DE JESUS DE SOUZA

Revista Análise Econômica

Av. Joảo Pessoa, 52

CEP 90040-000 PORTO ALEGRE - RS, BRASIL.

Telefones: (051) 316-3348 e 316-3440

Fax: (051) 225-1067 


\title{
AS CONTAS NACIONAIS E OS CUSTOS AMBIENTAIS DA ATIVIDADE ECONÓMICA
}

Charles C Muller

\begin{abstract}
SINOPSE
A crescente preocupação com os impactos ambientais da atividade económica nas sociedade contemporâneas acabou se refletindo no campo das estatísticas. Verificou-se que o sistema de contas nacionais, o sistema-sintese do funcionamento agregado das economias, é totalmente inadequado para medir os efeitos econômicos de tais impactos Atividades que aumentam a degradação ambiental freqüentemente são registradas como contribuiç̋̋es positivas à economia, e é contabilizada como crescimento a expansão apoiada na exaustăo de recursos naturais năo renováveis. Problemas dessa natureza vem originando um esforço, liderado pelas Naçőes Unidas e pelo Banco Mundial, de reformar o sistema, tornando-o apto a registrar adequadamente fenómenos desse tipo e a produzir indicadores que reflitam os impactos económicos da degradação ambiental promovida por atividades de produção e de consumo $O$ presente artigo objetiva avaliar os principais problemas com o atual sistema de contas nacionais, bem como divulgar uma proposta que esta sendo testada para a implementação de um sistema de contas satélites que permita ao sistema de contas nacionais contornar a maioria desses problemas
\end{abstract}

\section{INTRODUÇÃO}

O relatório da Comissão Brundtland, divulgado em 1987, teve dois efeitos fundamentais: mostrou que o crescimento económico com saúde ambiental ainda é possivel, atenuando o pessimismo sobre as perspectivas de nosso planeta que emanou da Conferência das Nações Unidas sobre Meio-Ambiente de 1972, em Estocolmo; e popularizou o conceito de desenvolvimento sustentável (ver WCED, 1987, cap. 2). Para a Comissão Brundtland, o desenvolvimento é tanto possível como desejável, desde que sustentável Há quem ofereça restrições ao otimismo do relatório da Comissão (Auroi, 1991), mas o conceito de desenvolvimento sustentável parece ter vindo para ficar.

Para ser sustentável, o desenvolvimento deve compatibilizar a crescente satisfação das necessidades de geração presente com a garantida manutenção da capacidade das gerações futuras de atender às suas necessidades. O problema é que o crescimento econômico das nações industrializadas vem exigindo o emprego de recursos naturais, alguns não renováveis e outros que vem se regenerando a taxas inferiores às atuais taxas de usos, bem como vem ampliando de forma preocupante a geraçăo de rejeitos e de poluição, responsável por crescente degradação ambiental. Ao mesmo tempo, as estratégias adotadas pelos países em desenvolvimento numa tentativa de aumentar os padrões de vida de suas populações, aliadas a altas taxas de expansão demográfica, contribuem para agravar a situação. O dilema de nosso tempo é o de encontrar estratégias factíveis

*Prof. Titular do Dep. Econ. UnB. Membro do Instituto Soc., População e Natureza, Brasilia

\begin{tabular}{|l|l|l|}
\hline Cód. AEA & Palavras-chave: contas nacionais, produto sustentável,
\end{tabular} 240 análise custo-beneficio.

\begin{tabular}{|l|l|l|l|}
\hline ANÁLISE ECONÓMICA & ANO 12 & março/setembro 95 & p. 66-99 \\
\hline
\end{tabular}


que compatibilizem a manutenção e o aumento gradual dos níveis de vida do mundo industrializado, com o necessário crescimento dos paises em desenvolvimento, e com o resguardo das opções de sobrevivência e de progresso das gerações futuras. O relatório da Comissão Brundtland deixa claro que, sem drásticas alterações dos atuais estilos de desenvolvimento, tanto dos países industrializados como dos em desenvolvimento, a sustentabilidade tornar-se-á inviável. A procura do desenvolvimento sustentável seria, assim, questão de sobrevivência. A crescente preocupação com esse estado de coisas vem se refletindo no campo das estatísticas. Demandas e pressões internas e internacionais fizeram surgir, principalmente nos países industrializados, sistemas de estatísticas ambientais, hoje ainda em fase de consolidação (Mueller, 1993). Semelhantemente, vem aumentando a insatisfação com a incapacidade do sistema de contas nacionais de fornecer indicadores que reflitam adequadamente aspectos de sustentabilidade do desenvolvimento, levando a um esforço, ainda não inteiramente consolidado, de reforma do sistema.

Ao examinar a evolução e o significado das tentativas em curso para introduzir no sistema de contas nacionais a dimensão ambiental, o presente trabalho objetiva discutir as principais deficiências que, na atual configuração, o sistema de contas nacionais (SCN) vem apresentando no que tange ao registro dos impactos das inter-relações entre economia e meio-ambiente, bem como informar sobre o sentido do esforço em curso de procura de solução para esses problemas. Trata-se de um trabalho de divulgação; objetiva disseminar entre profissionais e estudantes de economia aspectos ainda pouco conhecidos das deficiências da estrutura presente do SCN, bem como das tentativas para encontrar saídas para as mesmas. A próxima seção apresenta as implicações da falta de consenso a respeito de referencial teórico básico para o sistema de informações ambientais, incluindo, portanto, um sistema de contas nacionais que registre os custos ambientais das atividades econômicas; a seção 3 avalia as tentativas em curso de introduzir a dimensão ambiental no sistema de contas nacionais, a seção 4 apresenta exemplo numérico do sistema de contas satélites ambientais que está sendo desenvolvido no âmbito das Nações Unidas, e a seção 5 conclui discutindo os problemas para a atribuição de valores monetários aos impactos ambientais negativos da atividade humana.

\section{REFERENCIAL BÁSICO PARA UM SISTEMA DE INFORMAÇÕES AMBIENTAIS}

Inicia-se tratando de questão fundamental para a implantação, em bases sólidas, de um sistema de estatísticas ambientais: a da consolidação de referencial que oriente o processo de constituição do sistema

\subsection{As dificuldades de área nova no campo das estatísticas}

A produção de estatísticas e informações sistemáticas sobre o meio-ambiente requer um esforço multidisciplinar envolvendo elementos das ciências naturais, da economia, da demografia e da sociologia com o objetivo de: a) estabelecer as bases para a mensuração adequada dos impactos ambientais de fenômenos naturais $e$ das atividades humanas sobre o meio-ambiente, e deste sobre as condições de vida do homem; b) referir-se tanto ao meio-ambiente natural - isto é, ao ar, à água, aos 
solos, à vegetação, etc. - como ambiente construído pelas sociedades humanas, incluindo tanto os locais de residência e de trabalho como outros aspectos da fixação do homem no espaço e do desenvolvimento de suas atividades; c) Fornecer informações e sínteses de dados relevantes à formulação de estratégias e que privilegiem o desenvolvimento sustentável, bem como de políticas sócio-econômicas e ambientais integradas e coerentes.

Colocada desta forma a questão parece simples. Entretanto, as várias tentativas de levar avante iniciativas nesse sentido revelam que não são pequenas as dificuldades para a criação de um sistema ordenado e coerente de estatísticas e informações ambientais. A maioria destas dificuldades resulta da inexistência de consenso sobre um referencial para servir de base ao sistema. Como mostram Stapanian e Garner, 1989, as ciências ambientais são relativamente recentes e ainda atravessam um período de consolidaçăo. Controvérsias, algumas contundentes, vem impedindo o desenvolvimento de modelos de aceitação geral. Além disso, as técnicas de análise de dados dessas ciências são predominantemente intuitivas; ainda não se generalizou o emprego da estatística como instrumento de análise. Por sua vez, só recentemente as organizações de produção de estatísticas de alguns países vem se preocupando em criar um sistema estruturado de informações ambientais.

\subsection{0 papel de um referencial básico}

Um exemplo da importância de referencial teórico para a orientação da produção de estatísticas é o fornecido pelo próprio sistema de contas nacionais. Esse sistema-síntese apoia-se em referencial teórico claramente especificado - a macroeconomia keynesiana - que também fornece orientação a outros segmentos do campo das informações sócio-econômicas, um vez que as contas nacionais requerem estatísticas consistentes com seu esquema teórico básico Não seria, portanto, aconselhável produzir estatísticas ambientais ao acaso, ou numa cópia mecânica do que os outros países realizam. Um caminho para o desenvolvimento de moldura conceitual para um sistema de estatísticas ambientais é o de privilegiar as inter-relações entre os processos econômicos e o meio-ambiente. As preocupações com o meio-ambiente e a crescente necessidade de informações ambientais resultam, fundamentalmente, dos impactos detrimentais cada vəz mais acentuados, derivados do funcionamento do sistema econômico.

A análise de Goergescu-Roegen $(1966,1971,1977)$ sugere uma maneira de fazer isso. Este autor chamou a atenção para a visão parcial da análise econômica convencional, que concentra suas atenções exclusivamente sobre os processo de produção e de consumo, como se os impactos destes se esgotassem inteiramente dentro dos limites do sistema econômico, pouco tendo a ver com o sistema mais amplo no qual se insere. A análise econômica trata de forma superficial o fato de que o processo produtivo depende fundamentalmente de materiais ordenados e de energia livre encontrados na natureza, e que são apropriados e transformados, originando bens e serviços para o consumo - imediato ou diferido; e o fato de que os processos de produção e de consumo geram rejeitos, resíduos, que em essência, são matéria e energia degradados ou dissipados. Goergescu-Roegen foi um dos responsáveis pelo emprego da noção de entropia fora do campo da termodinâmica (Rifkin, 1980); essa noção é básica para se inserir a dimensão 
ambiental na análise dos processos de produção e de consumo.

Por não analisar os processos econômicos nesse contexto, por não considerar explicitamente o nexo entre as atividades de produção e de consumo de bens e serviços como os recursos naturais apropriados para a transformação, à sua montante, e com os rejeitos gerados à sua jusante, a teoria econômica convencional acaba alijando do seu campo de percepção os impactos ambientais dessas atividades. É como se estes fossem exógenos, devendo ser relegados a outras áreas. Da mesma maneira, ao se apoiar no referencial das contas nacionais, o sistema de estatisticas econômicas não têm orientação sobre como considerar as inter-relações entre a economia e o meio ambiente.

Um esquema preliminar para a construção de referencial básico para o sistema de informaçōes ambientais, na linha da contribuição de Georgescu-Roegen, é esboçado por Naredo (1987, esp. p. 70-74). A Fig. 1 resume a abordagem desse autor, vemos ali que o campo de abrangência dos processos econômicos é bem mais amplo do que o usualmente considerado pela análise econômica convencional; inclui uma etapa anterior, da disponibilidade e apropriação de recursos naturais (energia livre e materiais ordenados); inclui, também, uma etapa posterior, da geração e disposição de rejeitos (energia dissipada e materiais degradados). Entretanto não é simples introduzir em um modelo estas duas etapas. Para tal, são necessárias análises transdisciplinares e não se pode pretender reduzir tudo a valores pecuniários. Além disso, ela requer que se abandone o enfoque de tipo aduaneiro, comum à análise econômica convencional, que considera o território como um espaço amorfo, no qual se desenvolvem as atividades de produção e consumo. Neste espaço, ingressam elementos de outros sistemas como se fossem mercadorias vindas do exterior, e dele saem os rejeitos e residuos, como se algo fora do sistema os absorvessem sem maiores conseqüências. Além disso, a análise se desenvolve como se o sistema estivesse permanentemente em equilíbrio (Naredo, 1987, p.72). No modelo será essencial que se considere o território como suporte físico concreto, do qual não se pode abstrair os recursos, nem os rejeitos 
FIGURA 1- Elementos em um sistema de estatísticas ambientais

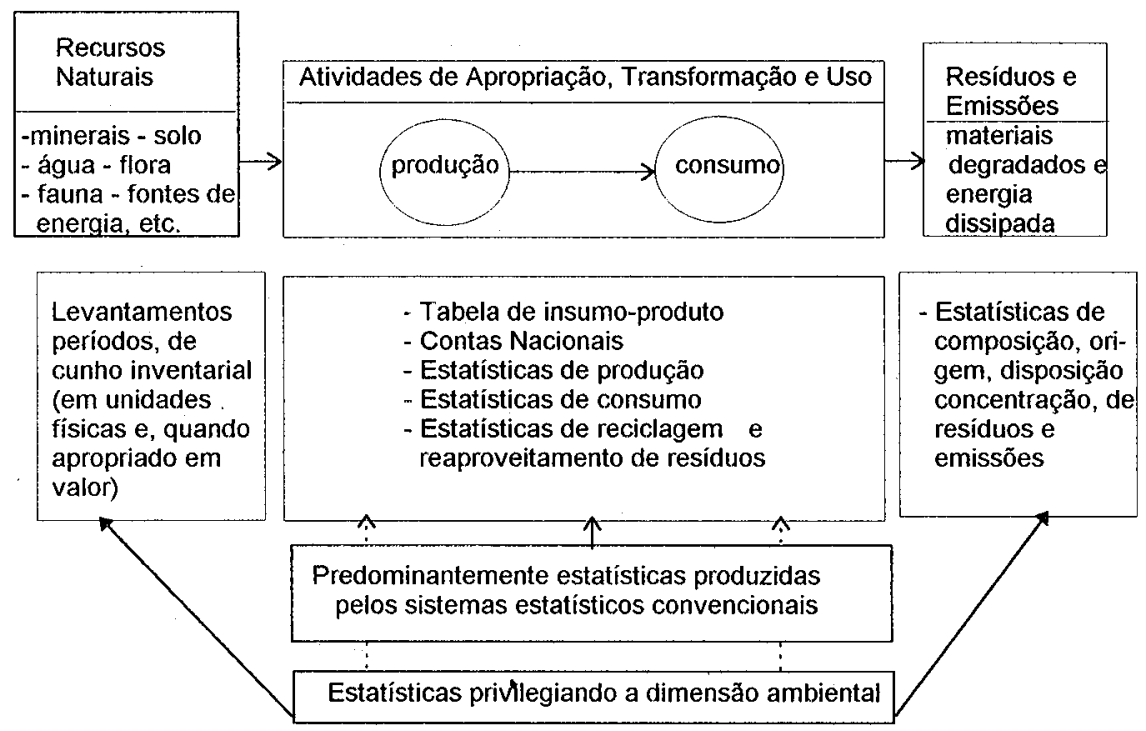

Um enfoque mais adequado dos processos econômicos exige, portanto, o envolvimento de disciplinas e técnicas de análise vinculados ao território. É fundamental, também, que a análise seja dinâmica e, particularmente, que se admita explicitamente a possibilidade entre os fluxos de energia e de materiais usados no processo de produção e de consumo e as taxas de renovação dos fundos nos quais tais fluxos se apoiam Para a análise de sustentabilidade é essencial que se possam determinar esses desequilibrios e medir sua magnitude.

Daí a importância de se desenvolver um referencial básico abrangente, que ressalte elementos que a análise convencional considera exógenos. Enquanto isso não acontecer, os sistemas de informações para o acompanhamento e à avaliação da sustentabilidade de processos sócio-econômicos centrais no mundo de hoje, tenderão a ser deficientes; isso é particularmente verdadeiro no que se refere ao SCN. Evidentemente, o esquema da Fig 1 não representa um referencial para estatísticas ambientais. Ele meramente aponta para os tipos de informação requeridos por abordagens do tipo da indicada por Georgescu-Roegen e por Naredo. Trata-se, porém, de esquema que pode ser aprofundado. Ademais, serve de base para a homogeneização de conceitos, definições, critérios e classificações, fundamental para a geração de informações e estatísticas úteis e consistentes e, de forma espacial, para que se façam adaptações corretas e significativas no sistema de contas nacionais. Como ressalta Naredo (1987, p.72), o problema hoje "não está tanto na ausência de informações" ambientais "como na sua dispersão, 
descoordenação, descontinuidade temporal ou parcialidade de enfoques, nomenclaturas e critérios, o que torna o seu emprego muito difícil", tanto em avaliações como para subsidiar o processo decisório.

As próximas seções apresentam avaliação das deficiências e problemas, do ponto de vista da sustentabilidade dos processos econômicos, de peça central do sistema estatístico - o SCN -, bem como examinam tentativa em curso de contornar tais problemas mediante a introdução de um sistema de contas satélites ambientais.

\section{A INTEGRAÇÃO DA DIMENSÃO AMBIENTAL AO SCN}

\subsection{Deficiências do atual sistema de contas nacionais}

Do ponto de vista da inter-relação entre a economia e o meio-ambiente, o problema com o atual SCN está em que ele não considera os impactos de uma gama de atividades que afetam significativamente a vida no nosso planeta nos dias de hoje. O SCN não registra as mudanças na qualidade do meio-ambiente provocadas pela ação humana, nem a redução ou esgotamento das reservas de recursos naturais não renováveis, ou os danos causados a recursos renováveis por exploraçäo predatória. Conseqüentemente, o sistema gera indicadores inconsistentes do ponto de vista da sustentabilidade do desenvolvimento. Seguemse alguns exemplos:

- Produto Interno Bruto (PIB) aumenta quando a produção de um país cresce às custas da redução no seu patrimônio de recursos naturais, e quando precisa efetuar esforços crescentes para extrair uma quantidade igual de recursos a partir de sua base de recursos naturais.

- Um surto econômico faz crescer o PIB e, simultaneamente, a degradação ambiental, com os custos que geralmente não são registrados.

- Os custos resultantes dos danos à saúde humana causados por aumento da poluição decorrente da expansão econômica, geram um incremento do PIB Aumentos de gastos com médicos e hospitais provocados pelo aumento de poluição são tratados como se representassem elevação de bem-estar social.

- Aumentos dos gastos no controle da poluição e na regeneração ambiental provocam aumento no PIB. ${ }^{1}$

- O desmatamento realizado na Amazônia por empreendimentos agropecuários incentivados, com forte destruição do patrimônio natural, é atividade de investimento e, portanto, contribui para $\mathrm{O} \mathrm{PIB}$, mesmo se no futuro esses empreendimentos pouco produzirem. O SCN não computa a perda de patrimônio natural ocasionada por tais ações

Problemas desta natureza têm gerado crescente insatisfação em relação ao SCN. Há basicamente duas linhas de criticas ao sistema: a dos que consideram o SCN insuficiente, mas passivel de reformulação, $e$ a dos que, apontando para problemas de base, julgam o sistema de difícil recuperação. A seguir examina-se, resumidamente, o pensamento representativo de cada uma dessas linhas.

\footnotetext{
1 Um estudo realizado na Repüblica Federal da Alemanha estabeleceu que os custos de defesa e regeneração do meio-ambiente em proporção ao PIB aumentaram de 5\%, em 1970, para cerca de $10 \%$, em 1985 . Houve, no período, uma expansão de quase $150 \%$ nesses custos, para aumento de $40 \%$ do PIB. Como as atividades de defesa e regeneração são incluídas no cálculo do PIB, ocorreu o paradoxo de custos crescentes para evitar ou reduzir a deterioração das condiçōes de bem-estar aparecerem como fator de crescimento, de aumento desse bem-estar (citado em Walschburger, 1990, p 4).
} 


\subsubsection{O SCN como incompleto, mas passivel de reforma}

Para Naredo (1987), o atual SCN sofre de "reducionismo pecuniário", que decorre da perspectiva estreita da teoria econômica em que se apóia. Assim, o sistema registra informações sobre uma parcela limitada de um todo muito mais amplo que, inspirado nos fisiocratas, o autor denomina "economia da natureza". O âmbito da "economia da natureza" é toda a biosfera e o conjunto de recursos de todos os tipos, sejam eles valorados ou não. $O$ enfoque econômico convencional, por sua vez, considera apenas uma pequena parte deste todo - a produção de bens e serviços reais, e o seu consumo, presente ou diferido. Além disso, essa parcela é tratada como se fosse autônoma, pouco tendo a ver com os elementos excluídos da análise

O conhecido "fluxo circular" da macroeconomia ilustra esse ponto. Conforme mostra Daly (1990) é como se a economia fosse um sistema isolado dentro do qual circula um "valor de troca", totalmente dissociado das dimensões físicas dos bens e recursos produtivos transacionados. Esse "valor de troca" flui em círculo entre empresas e familia e não se colocam problemas de esgotamento de recursos naturais e de poluição ambiental. Não se estabelece nenhuma relação entre sistema econômico e meio-ambiente Ignoram-se totalmente as trocas de matéria e energia entre o sistema econômico e o meio-ambiente ilustradas na Figura 1 . $E$, uma vez que o SCN é calcado na macroeconomia convencional, este se desenvolveu como se não houvesse impactos ambientais dignos de registro.

Para Naredo, o trágico é que, limitado o seu enfoque estritamente sobre as atividades de produção propriamente ditas a economia convencional afasta de nossa preocupação o restante. Não se trata de uma mera simplificação, das habituais às ciências. Ao se ignorarem as inter-relações da economia com o meioambiente, a tendência é a de se supor que, no domínio das ações de produção e de consumo qualquer coisa pode ser feita, desde que não haja redução no estoque de recursos produtivos fabricados pelo homem. É como se o sistema econômico fosse independente do ecosistema.

Para que se elimine a hipótese da independência entre o sistema econômico e os sistemas mais amplos com os quais interage, é fundamental que se modifique a análise econômica convencional $e$, consequientemente, o sistema de contas nacionais, é essencial que os registros contábeis do sistema considerem pelo menos os aspectos mais relevantes das inter-relaçöes entre a economia e o meioambiente. Cumpriria, assim, transformá-lo tornando-o instrumento útil à análise dos impactos da atividade econômica sobre o meio-ambiente e para fornecer indicadores apropriados a avaliações da sustentabilidade do desenvolvimento.

\subsubsection{Não vale a pena tentar recuperar o SCN}

Um autor representativo desta linha é Richard Norgaard Avaliando o sistema de contas nacionais (ver Norgaard, 1985), conclui que não vale a pena despender esforços em sua reforma - pelo menos não para torná-lo peça central de um sistema de registro e avaliação das inter-relaçōes entre a economia e o meio-ambiente, que considera fundamental seja estabelecido Para o autor, a reforma do SCN parte da premissa de que o sistema é essencialmente consistente e que basta ampliá-lo para incluir elementos da dimensão ambiental. Norgaard considera falsa essa premissa. Argumenta que o SCN possui problemas de base que prejudicam essa alternativa. 
O principal deles é que o sistema evoluiu de duas teoria logicamente inconsistentes: a microeconomia neoclássica e a macroeconomia keynesiana Essas inconsistências foram contornadas com convenções e artifícios; mas elas permanecem, retirando validade às tentativas de reforma.

Um outro problema estaria na determinação dos valores, em termos sociais, de elementos ambientais. A lógica do SCN requer que estes sejam expressos em termos monetários, calculados com base em transações de mercado "refletem as instituições sociais vigentes que definem a posse de riqueza e o poder econômico e facilitam certas atividades e tecnologias enquanto restringem outras" (Norgaard; 1985 , p 3). Se a introdução da dimensão ambiental no SCN tem como objetivo torná-lo apto a contribuir para apontar falhas nas instituições vigentes em tratar adequadamente problemas do meio-ambiente, o emprego de valores efetivamente registrados nos mercados para adicionar ao sistema de elementos ambientais acabaria incorporando essa falhas ao novo $\mathrm{SCN}$, tornando-o ainda mais inadequado do que é.

A terceira objeção do autor é a de que, para incluir elementos ambientais no SCN teríamos que conhecer com segurança as formas de inter-relação entre a economia e o meio-ambiente. Para Norgaard, o problema é que "não temos um modelo de como as economias se relacionam a sistemas ambientais para nos guiar na captura e definição de interações que sejam sustentáveis" (Norgaard, 1985, p. 3). O estado do conhecimento nessa área é precário e é reduzida a nossa habilidade de realizar sínteses que nos orientem na inclusão de elementos ambientais no sistema de contas nacionais.

Levados ao extremo, os argumentos de Norgaard sugerem o abandono das tentativas de aprimorar o sistema de contas nacionais, e o desenvolvimento, em seu lugar, de indicadores de outra natureza para avaliações de aspectos da interrelação da economia com o meio-ambiente

\subsubsection{Uma avaliação das duas posições}

As críticas de Norgaard ao SCN estão na linha de objeções antigas sobre o significado e a validade dos principais indicadores que o sistema produz. Apesar de tais objeções, os paises continuam a realizar levantamentos de contas nacionais e a investir no seu aperfeiçoamento. Isso não significa que não existam problemas mas sim que, sem alternativa mais eficiente, continua-se com o SCN.

Na verdade, a maior dificuldade está no uso que é feito dos indicadores do SCN. Se, na avaliação da evolução de uma economia, estes forem empregados isoladamente como termômetros de desenvolvimento, de melhoria de bem-estar social, se forem ignoradas outras estatísticas e informações e a análise se concentrar apenas na evolução do PIB - total ou per capita -, o resultado será claramente deficiente. Entretanto se usados em conjunção com outros dados e informações, os indicadores do SCN podem ser úteis. Nesse contexto, merece apoio o esforço em curso para reformar o $\mathrm{SCN}$, visando reduzir as principais distorções atualmente existentes. Se essa tentativa tiver êxito, o sistema passará a gerar indicadores úteis para avaliações, feitas em conjunção com outros dados e informações, de aspectos da sustentabilidade do desenvolvimento.

Em certo sentido, ao reconhecer que não existe sistema que possa substituir com vantagem o SCN, até Norgaard $(1985$, p. 14-17) aceita essa posição. Para o 
autor, a economia e a ecologia vem desenvolvendo uma variedade de modelos, não pelo prazer de criar coisas diferentes, mas porque nenhuma das disciplinas achou, ainda, um modelo adequado tendo em vista a complexidade dos sistemas, cujo funcionamento procuram explicar e a variedade de perguntas que são feitas e de problemas que são tratados. Por isso mesmo, recomenda a constituição de "sistemas múltiplos de contas e indicadores, cada um com pontos fortes e deficiências" (1985, p. 15). Nesse contexto o autor provavelmente não rejeita o SCN modificado e aperfeiçoado. Evidentemente, não concordaria em torná-lo o sistema central de análise de questões do desenvolvimento sustentado.

$\mathrm{Na}$ verdade, os técnicos envolvidos na criação de um sistema de contas satélites ambientais comungam com esse ponto vista. Salah EI Serafy, por exemplo, um dos coordenadores dos trabalhos, reconhece que, mesmo depois de completadas a revisão do $\mathrm{SCN}$ e a criação do sistema de contas satélites ambientais em curso, muito ainda restará a ser feito na área das estatísticas e informações ambientais, dentro e fora do sistema de contas nacionais. Concorda que os avanços são parciais, representando passo modesto, mas recomenda enfaticamente que o novo esquema seja introduzido sem demora, deixando para aperfeiçoá-lo à medida que se ganhe experiência e que se aprofunde a compreensão das inter-relações entre economia e meio-ambiente. "Não se deve esperar que todo o espectro de questões ambientais venha a ser coberto. É fundamental introduzir logo aquilo que se conhece, ajustando os dados de renda parcial e gradualmente, e não ficar esperando até que todas as perguntas sejam respondidas"(El Serafy, 1990, p.9). Nesse contexto, merece apoio o esforço em curso de aprimoramento do SCN, com a introdução de aspectos da dimensão ambiental. As características gerais do novo sistema são apresentadas a seguir.

\subsection{A revisão em curso do $S C N$}

Objetivando capacitar o SCN a produzir indicadores apropriados para avaliações da evolução da economia sob o prisma do desenvolvimento sustentável, está sendo construído, no bojo da revisão em curso do Sistema de Contas Nacionais das Nação Unidas (SCN-UN) - que fornece recomendações aos países sobre a metodologia de cálculo das contas nacionais - um conjunto de contas satélites ambientais a ser conectado ao corpo principal do sistema.

A última revisão do SCN foi finalizada em 1968 e está em curso uma nova, a ser submetida à Comissão de Estatísticas das Nações Unidas em 1993 (El Serafy, 1990, p.6). Essa revisão não pretende revolucionar o SCN, mas sim aprimorá-lo A questão da introdução da dimensão ambiental no sistema, por exemplo, vem sendo tratada de forma cautelosa. Houve forte resistência do establishment das contas nacionais, até mesmo em considerar essa questão, mas depois do empenho decidido de um grupo de técnicos, sob patrocínio do Banco Mundial e do Programa das Nações Unidas para o Meio-Ambiente (PNUMA) e com a participação do Escritório de Estatística das Nações Unidas, prevaleceu o ponto de vista de que as contas do núcleo do SCN devem permanecer essencialmente como são hoje, permitido a comparabilidade no tempo, mas que seja criado um conjunto de Contas Satélites Ambientais, ligadas ao núcleo do SCN para permitir a geração de indicadores agregados que reflitam as inter-relações entre economia e meioambiente A decisão de não alterar o corpo básico do SCN tem sido repetidamente 
enfatizada O manual revisado para o sistema de contas nacionais, correntemente em elaboração pelo Escritório de Estatística das Nações Unidas, incluirá recomendações para implantação pelos paises de um sistema de Contas Satélites Ambientais. Já estão inclusive sendo desenvolvidos estudos de caso para teste do novo esquema (El Serafy, 1990, p.7). Segue uma descrição dos elementos básicos do sistema de contas satélites

\subsubsection{Registros de variações do patrimônio de recursos naturais}

Uma das principais inovações do sistema de contas satélites ambientais é a que procura corrigir o tratamento assimétrico que o $\mathrm{SCN}$ dá aos recursos produtivos construidos pelo homem (bens de capital) e aos recursos naturais que este emprega Os indicadores agregados do atual SCN refletem a maneira como os primeiros são usados, como estes aumentam e como se depreciam, mas ignoram boa parte dos efeitos do uso dos recursos naturais sobre o patrimônio econômico Um país pode "crescer" com base em rápida exaustão de suas reservas minerais, ou mediante exploração destrutiva de seus recursos naturais renováveis sem que isso seja captado pelo SCN - não obstante os impactos detrimentais dessa forma de "crescimento" sobre a evolução futura da economia. Uma melhoria passageira de consumo e de bem-estar estaria sendo conseguida às custas do sacrifício do consumo e bem-estar futuros, mas o SCN não emitiria sinais a respeito à sociedade As contas satélites ambientais objetivam eliminar essa deficiência, possibilitando o registro explícito das variações que introduzem no patrimônio de recursos naturais de um pais Para tal, é estabelecida ligação entre os fluxos de usos desses recursos e seus estoques, partes que são do patrimônio físico do pais.

$O$ ideal seria que se fizesse periodicamente um levantamento detalhado desse patrimônio, registrando no início e no fim do ano as magnitudes físicas e principalmente para o novo SCN - o seu valor. Com isto seria possivel medir as reduções no valor desse patrimônio causadas pelo seu uso no processo de produção e de consumo, bem como os incrementos possibilitados pela regeneração ou crescimento vegetativo de recursos naturais renováveis, e pela "descoberta" ou adição de novas reservas de recursos naturais Trata-se, entretanto, de tarefa complexa e de grandes proporções que nem todos os paises podem realizar

O SCN modificado por contas satélites permite, porém, o registro de variaçōes no tempo do patrimônio de recursos naturais. Parte-se do ponto feito do por Naredo, de que o conjunto de recursos naturais disponiveis de um país é muito maior do que o conjunto de recursos apropriados e usados em um dado momento. Com o sistema de contas satélites o SCN torna-se apto a medir o processo de apropriação de recursos naturais (a sua valoração, quando possivel, é feita com base em preços de mercado ou é imputada) bem como sua utilização e destruição pelos agentes econômicos. Isso é feito mediante um sistema de contas registrando, no segmento de uso final do SCN, as variações do patrimônio tangível da economia.

As contas de patrimônio tangível do novo sistema incluem, além dos registros das variações do patrimônio econômico renovável (capital fixo e estoques) habitualmente tratadas pelo $\mathrm{SCN}$-, os das variáveis do patrimônio de recursos naturais não renováveis. Ademais, contêm um sistema de registros de transferências de ativos, do patrimônio ambiental para o patrimônio econômico. 


\subsubsection{Os custos ambientais}

Em essência, são dois os tipos de custos ambientais a serem considerados pelo sistema de contas satélites ambientais: os custos de depleção de recursos naturais - um dos objetos de um sistema de registro de patrimônio ambiental -, e os custos da degradação ambiental

\section{i. Os custos de depleção de recursos naturais}

O termo depleção é empregado aqui para significar redução da disponibilidade de recursos naturais. Não se trata de mais um anglicismo; o Novo Dicionário Aurélio da Língua Portuguesa define depleção como a diminuição da quantidade de humores do organismo; por sua vez, humor (do latim humore) significa líquido. Para a fisiologia, humores são líquidos contidos em um corpo organizado. Por analogia, portanto, depleção, traduz a noção de redução que pode ser gradual ou não, de elementos vitais do meio-ambiente. Trata-se de termo mais apropriado que os termos esgotamento ou exaustão, estes se referem a processo em estágio avançado de depauperação de recursos. Entretanto, a depleção ocorre mesmo quando um dado recurso natural não renovável ainda é abundante.

Pode haver depleção tanto de recursos naturais não renováveis como daqueles condicionalmente renováveis. A depleção de recursos naturais não renováveis ocorre, de forma óbvia, no de setor de mineração. Quando se extrai recursos minerais há uma redução do patrimônio ambiental do país, que passa a ser medida pelo sistema de contas satélites. Entretanto, ao usar destrutivamente o solo, a agricultura também origina a depleção, embora esta seja mais difícil de medir. Por outro lado, novas descobertas de recursos minerais representam adições ao patrimônio econômico do país; o mesmo acontece com a incorporação de novas terras à agricultura em áreas de fronteira agrícola. O sistema de contas satélites trata esses fenômenos como transferência do patrimônio ambiental ao patrímônio econômico. Uma outra forma de depleção é a que resulta da exploração destrutiva de recursos naturais condicionalmente renováveis. Executada racionalmente, as atividades de pesca ou de extração de madeira em florestas nativas, por exemplo, não esgotam recursos naturais. Entretanto, se essas atividade extraem mais recursos do que o permitido pelas taxas de renovação natural, há depleção. Algo semelhante pode ocorrer com o uso de água e com outros recursos potencialmente renováveis; uma exploração destrutiva, impedindo que esses recursos se regenerem, causa depleção.

\section{ii. A mensuração dos impactos da degradação ambiental}

O novo sistema também trata dos custos de degradação do meio-ambiente, tanto decorrentes das atividades de produção e de consumo, como de cataclismas naturais (terremotos, enchentes). Na verdade, em sociedades industrializadas, estes são responsáveis por parcela predominante dos custos ambientais São custos resultantes, tanto de atividades de proteçăo e resguardo contra a degradação ambiental, como os decorrentes de danos específicos causados pela poluição ou por outras formas de degradação.

Determinados os custos ambientais gerados pelas atividades de produção e de consumo de bens e serviços, torna-se possivel calcular o Produto interno Bruto Sustentável (PIBS), o Produto Interno Líquido Sustentável (PILS), e outros 
indicadores especiais para a análise do desenvolvimento sustentável

A introdução da dimensão ambiental no SCN pode ser melhor compreendida a partir de um exemplo numérico simplificado, ressaltando algumas mudanças que se pretende introduzir. É o que se faz na próxima seção.

\section{AS CONTAS SATÉLITES AMBIENTAIS - UM EXEMPLO}

\subsection{As principais caracteristica do novo sistema}

Tendo participado ativamente dos grupos de trabalho para a criação da metodologia das contas satélites ambientais, três técnicos - dois do Escritório de Estatística das Nações Unidas (UNSO) e um do Escritório Federal de Estatística da República Federal da Alemanha - construíram um exemplo numérico visando submeter a nova metodologia à discussão, e para servir de base para o Manual de Contabilidade Ambiental, a ser publicado pelo UNSO (ver Bartelmus et al., 1989).

O exemplo focaliza a economia de um país "essencialmente fictício, mas concebido com base em hipóteses razoáveis" (Bartelmus et al., 1989). Trata-se de um país em desenvolvimento, com alguma disponibilidade de petróleo para exportar, mas que também possui importante setor agrícola, pesca e extração vegetal (a madeira é explorada a partir de florestas nativas); possui, também, um setor manufatureiro voltado à transformação de produtos agrícolas e ao refino do petróleo, mas que está engajado em substituir importações. O seu setor serviços inclui atividades de comércio e transporte, com uma importante participação da distribuição de petróleo e derivados. Evidentemente, possui um setor governo.

A estrutura básica do sistema de contas satélites desenvolvido para avaliar aspectos da inter-relação entre a economia e o meio-ambiente do país hipotético apoia-se em duas tabelas uma, de oferta total e setorial, tanto de origem interna como importada (Tab 1), e uma tabela de uso de insumos de valor adicionado e de demanda final (Tab.2). Tratam-se, na verdade, de versões modificadas e ampliadas de tabelas do SCN tradicional, construídas com a inclusão de contas satélites. Essas tabelas são detalhadas nas duas próximas seções; antes, entretanto, são apresentadas as principais inovações do novo sistema

\section{Mudanças nas contas de patrimônio do país}

Do ponto de vista da análise da sustentabilidade do desenvolvimento, a principal inovação do novo sistema está na inclusão no bloco "acumulação de patrimônio tangivel do país", além dos tradicionais capital fixo (máquinas, equipamentos, etc.) e estoques de mercadorias, parte do patrimônio líquido reproduzivel do país, elementos de seu patrimonio natural como a terra, o solo empregados em atividades agropecuárias e em estradas, represas e outras estruturas e construção - bem como as reservas de petróleo e de outros recursos minerais, do seu subsolo (Bartelmus et al., 1989, tabela II). Isso é feito para que se possa determinar as mudanças que, no período de análise, ocorrem na disponibilidade de recursos naturais do país. Todos esses elementos são valorados e admitem o cálculo de depreciação, como já acontece com o capital fixo.

O patrimônio tangivel é assim, decomposto em patrimônio econômico e em patrimônio ambiental. Ademais, foram criadas formas de interligar estes; quando se descobrem novas reservas de recursos naturais, por exemplo, há transferências do 
patrimônio ambiental ao patrimônio econômico; por sua vez, catástrofes naturais transferem, por assim dizer, recursos do patrimônio econômico ao ambiental.

\section{Serviços de proteção ambiental}

O sistema de contas satélites inova ao separar a produção de "serviços de proteção ambiental" da produção de outros bens e serviços. Por hipótese, todos os setores da economia desenvolvem atividades de proteção ambiental, mas a maioria - faz para uso próprio. O fornecimento de serviços de proteção ambiental a outros segmentos da economia é feito apenas por três setores: o setor outros serviços; o setor comércio e transporte, e o setor governo (ver adiante). Os demais adquirem o serviço de proteção ambiental que estes três setores produzem e fornecem a eles insumos, equipamentos e serviços para a manutenção e ampliação da sua capacidade de geração de serviços de proteção ambiental

Via de regra, o governo não "vende" a sua produção de serviços ambientais. Ao efetuar despesas na recuperação do meio-ambiente (na limpeza de rio poluído, ou de área fortemente degradada, por exemplo), o governo melhora o meio-ambiente sem esperar retribuição pecuniária; o valor da "produção" dessas atividades de recuperação ambiental é, por convenção, igual ao seu custo. Se o governo pode atuar na recuperação do meio-ambiente, ele também o degrada ao desenvolver "outras atividades". A sua atuação nesses dois campos é registrada pelo sistema de contas satélites e o saldo pode ser tanto positivo como negativo.

Os autores fazem a hipótese heróica de que, ao serem gerados, os serviços de proteção ambiental não provocam degradação ambiental. Esta resulta inteiramente das outras atividades produtivas dos vários setores e das atividades de consumo (Bartelmus et al., 1989, p.28).

\section{O consumo e o meio-ambiente}

O sistema de contas satélites inova ao registrar separadamente os gastos das famílias em bens e serviços que empregam na proteção ambiental - materiais de limpeza, filtros, combustiveis tratados para reduzir a poluição, ${ }^{2}$ etc. Para tal, foi criada uma coluna para atividades ambientais do setor famílias na tabela de uso de insumos (Tabela 2) Por convenção, o setor famílias nada produz; contudo, ele usa insumos de proteção ambiental e esse uso é registrado pelo novo sistema, que também estabelece, separadamente, o impacto de atividades de degradação ambiental das famílias. No SCN tradicional, a aquisição de insumos e serviços de proteção ambiental das famílias é parte da demanda final; no novo sistema, ele passa a ser consumo intermediário.

Outra novidade está na medição separada dos gastos das famílias com médicos, remédios e hospitais, em decorrência dos danos à saúde causados pela poluição, bem como com a recuperação dos itens de seu patrimônio de deterioração por condições ambientais adversas. Em outros termos, os gastos de consumo são decompostos em dispêndios que as familias são forçadas a realizar em decorrência da degradação ambiental, e em outros dispêndios de consumo. Entretanto, ambas

\footnotetext{
${ }^{2}$ Um exemplo está no carvão mineral tratado para minimizar emissões poluentes, usado no aquecimento residencial em partes das IIhas Britânicas O Clean Air Act proibiu o uso do coque bruto, exigindo o desenvolvimento do carvão tratado. Entretanto, este é bem mais dispendioso, o seu emprego produziu considerável aumento no custo de calefação das residéncias aquecidas a carvão .
} 
as categorias de gastos são parte da demanda final. O novo sistema é tímido ao não retirar desta os gastos resultantes da degradação.

\section{A depleção de recursos naturais}

Apontamos acima a forma pela qual o novo sistema trata deste elemento. $O$ exemplo detalha o registro desse tipo de custos ambientais, bem como as contas criadas especialmente para este fim.

\section{A mensuração dos impactos da degradação ambiental}

As atividade de produção e de consumo dão origem a várias formas de degradação ambiental. Algumas podem ser medidas e há como atribuir a elas valores monetários. Outras, entretanto, são difíceis de ser em mensuradas para uso no sistema de contas satélites. Isso ocorre, por exemplo, com partes significantes da poluição do ar, da água e dos solos nas sociedades modernas. Bartelmus et al., 1989 (p.13 e 22), sugerem que a medição desse tipo de poluição seja feita com base em metodologia dos custos requeridos para manter determinado padrão de qualidade ambiental.

Um problema com a inclusão no novo SCN dos impactos da poluição e de outros elementos de degradação ambiental é que, muitas vezes, não há como determinar de forma inequivoca a parcela destes que cabe a cada setor produtivo ou ao setor de famílias. As emissões à atmosfera em um centro urbano-industrial, por exemplo, ocorrem de forma simultânea, e há efeitos de interação entre elas, e dessas emissões com fenômenos naturais. Isso acontece, por exemplo, no caso das chuvas ácidas. Por esse motivo, como se verá adiante, o sistema de contas satélites deixa de atribuir impactos ambientais a segmentos específicos, tratando-os para o conjunto da economia. Em muitos casos, porém, a degradação ambiental pode ser inequivocamente atribuida a setores especificos. $O$ setor de mineração, por exemplo, além de produzir depleção de recursos naturais, gera degradação. 'É o que acontece com a mineração a céu aberto (os garimpos da Amazônia são exemplos eloqüentes). No novo SCN os custos reais ou potenciais de recuperação desse tipo de degradação são computados e incluídos como parte dos custos ambientais produzidos pelo setor mineração. Algo semelhante ocorre com a degradação específica de cada um dos outros setores produtivos.

Já se mencionou a degradação causada pelo setor familias Nas suas atividades de consumo estas poluem; há a disposição irregular do lixo e de entulhos, a queima de certos combustiveis e rejeitos e o uso de veículo que geram emanações nocivas à atmosfera, entre outras formas de poluição. O novo SCN pretende captar os custos dessas formas de degradação ambiental e atribui-los especificamente ao setor. Para tal, considera que embora, por convenção, as famílias não produzam bens e serviços, elas "produzem" degradação; registra, assim os seus custos. O setor governo, com suas atividade de "consumo", gera degradação ambiental e o tratamento desta é semelhante. Entretanto, como vimos, o governo também pode produzir recuperação ambiental e há um efeito líquido das atividades de degradação e de regeneração do governo.

\section{Desastres naturais}

A degradação ambiental não emana apenas das atividades de produção e de consumo A própria natureza, mediante cataclismas e outros distúrbios, provoca, além de degradação ambiental, destruição do patrimônio econômico. Um terremoto, 
uma enchente, a erupção de um vulcão geram efeitos desse tipo e o sistema de contas satélites está capacitado a registrar, em parte pelo menos, os seus impactos econômicos. Vimos que, nesses casos, a destruição e a degradação são tratadas como transferências do patrimônio econômico ao patrimônio ambiental.

Segue-se o exame das duas tabelas que compõe o novo SCN, bem como a análise do seu uso na determinação de indicadores das contas nacionais que consideram aspectos da dimensão ambiental. Esse exame será feito com base em versões compactas. Bartelmus et al. (1989) apresentam tabelas em nivel de detalhe consideravelmente maior do que o das tabelas deste trabalho. Entretanto, o seu manuseio é complicado, tornando difícil o seu uso para ilustrar a discussão. Ressalte-se entretanto que, na versão aqui apresentada, foi mantido o essencial.

\subsection{A tabela de oferta}

$\mathrm{Na}$ tabela de Oferta de Bens e Serviços do sistema de contas satélites ambientais (Tabela1) os produtos e serviços estão nas linhas e os setores de atividade nas colunas. Ela registra o valor da produção no período de análise, tanto total como setorial. É instrumento básico de cálculo do valor adicionado, e a partir deste, de outros indicadores agregados da economia. Os produtos e serviços são reclassificados para destacar elementos de interesse da análise dos impactos ambientais da atividade econômica; são as seguintes as grandes categorias:

i. Serviços de proteção ambiental (SPAs). Categoria criada para possibilitar avaliações da contribuição específica das atividades de proteção ambiental para a produção, para a renda, para o emprego e para o processo de formação de capital.

ii. Produtos de crescimento natural (PCNs). Inclui a parte da produção do setor agricultura, atividades florestais e pesca que resulta da exploração de recursos naturais renováveis, bem como de transporte e a comercialização destes. $\mathrm{O}$ registro em separado dos PCNs é importante, pois permite determinar os fluxos anuais de produção e de renda gerados a partir de recursos naturais renováveis e, especialmente, avaliar sob o prisma da sustentabilidade do desenvolvimento, as atividades que se apoiam nesse tipo de recursos.

iii. Outros bens e serviços: os demais bens e serviços produzidos ou importado pela economia.

Tabela 1: Oferta total e setorial (produção e importação). Em bilhões de UM

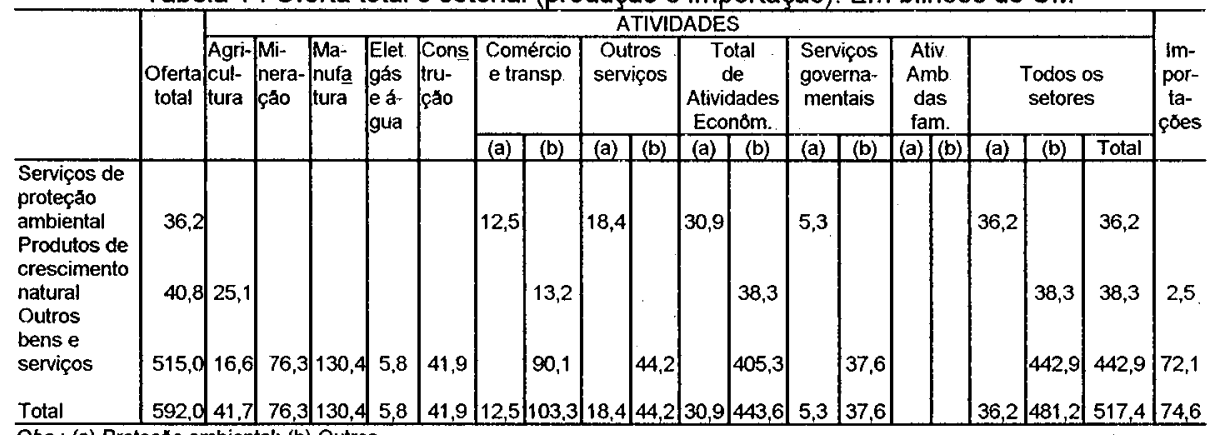

Obs : (a) Proteçăo ambiental; (b) Outros 
A classificação das atividades da tabela de produção compreende os seguintes setores: Agricultura, atividades florestais e pesca; Mineração; Manufatura; Eletricidade, água e gás; Construção; Comércio e transporte; Outros serviços; e Serviços governamentais A novidade está na inclusão, em adição a estes, da categoria "Atividades ambientais do setor famílias". Este setor nada produz, mas usa insumos na proteção ambiental e gera degração ambiental, razão porque é considerado separadamente

As atividades de cada setor se decompõe em "atividades de proteção ambiental" e em "outras". A importância desta divisão ficará clara no exame da tabela de demanda intermediária, demanda final e valor adicionado (Tabela 2).

Como já se indicou, os SPAs são gerados e vendidos, ou postos à disposição do público, predominantemente pelos setores:

- Outros serviços, a partir de empresas de tratamento, reciclagem e disposição de resíduos e rejeitos, e de consultoria ambiental.

- Comércio e transporte, com o transporte de residuos e rejeitos aos núcleos de reciclagem, tratamento e disposição.

- Governo, com serviços de tratamento e disposição de rejeitos sanitários (lixo, esgotos, etc) e com obras e serviços de regeneração do meio ambiente.

Uma observação sobre o item "produtos de crescimento natural" do setor Agricultura, atividades florestais e pesca: este inclui apenas os resultados das atividades controladas pelo homem e que respeitem o princípio da sustentabilidade. Como exemplo temos a produção de madeira e extração vegetal controladas, isto é, mediante um manejo sustentado das florestas, e a produção pesqueira que não causa a depleção dos estoques básicos. A parte da produção do setor que não obedece a essa condição é incluida na categoria de "outros bens e serviços".

Como se verá adiante, quando atividades de exploração de recursos naturais geram perda de sustentabilidade, em consequeencia do desgaste dos estoques básicos, o sistema de contas satélites avalia e registra esse fato. Algo semelhante pode ser feito sempre que, por exemplo, o abate de animais de uma dada categoria excede o limite sustentável, causando depleção do rebanho. Nesse caso ela, atingiria, não o patrimônio natural, mas o "patrimônio produzido" da economia.

A Tabela 1 mostra que a economia hipotética do exemplo teve, no período de análise, uma oferta total de bens e serviços de 592 bilhões de unidades monetárias (UM); desse total, 517, 4 bilhões de UM se originaram nas atividades econômicas internas e 74,6 bilhões foram importados. A oferta de Serviços de Proteção Ambiental (SPNs) somou 36,2 bilhões de UM, a de Produtos de Crescimento Natural (PCNs), 40,8 bilhões, e a de outros bens e serviços, 515 bilhões de UM.

Os SPAs foram gerados pelos setores comércio e transporte (12,5 bilhões de UM), outros serviços (18,4 bilhões) e governo (5,3 bilhões). Os PCNs, por sua vez, se originaram dos setores agricultura, atividades florestais e pesca $(25,1$ bilhões de UM) e comércio e transporte (13,2 bilhões)

\subsection{A tabela de uso de insumos e produtos e de valor adicionado}

A Tabela 2, Uso de Insumos, Demanda Final e Valor Adicionado, mostra como os elementos transferidos do meio-ambiente ao patrimônio econômico, se distribuem entre vários tipos de usos. Os dados de oferta são os da Tabela 1, e os referentes aos elementos do meio-ambiente apropriados pela esfera econômica são 
os da coluna "transferência o patrimônio ambiental ao patrimônio econômico". A Tabela 2 contém informações sobre o uso que, no periodo de análise, atividades produtivas usuários finais fizeram dos bens e serviços e dos elementos do meioambiente (consumo intermediário, consumo das famílias e do governo, acumulação de patrimônio tangivel e exportações).

\subsubsection{O bloco de consumo intermediário}

O primeiro bloco da Tabela 2 descreve o uso de bens e serviços intermediários pelos diversos setores de atividade, num total de 243,0 bilhões de unidades monetárias (UM). As categorias de bens e serviços são as mesmas da Tabela 1; há um consumo intermediário de serviços de proteção ambiental de 36,2 bilhões de $\mathrm{UM}_{i}$ de produtos de crescimento natural num total de 23,0 bilhões, e os insumos incluidos na categoria de outros bens e serviços somam 183,8 bilhões Este bloco é semelhante ao empregado pelo atual $\mathrm{SCN}$ no cálculo dos seus indicadores $A$ novidade está na inclusão dos gastos de proteção ambiental do setor famílias $(13,9$ bilhões de UM) e do governo (um gasto líquido de 2,4 bilhões de UM) na categoria de uso intermediário, e não na de uso final como o faz o atual SCN. Como vimos, tais gastos têm como objetivo combater a degradação do meio-ambiente, não fazendo sentido inclui-los no consumo final.

\subsubsection{A demanda final}

O bloco de Demanda final da Tabela 2 é composto dos tradicionais consumo das famílias e do governo (198,4 bilhōes de UM), formação bruta de capital fixo ( 69,3 bilhões), variação de estoques $(7,3$ bilhões), e exportações $(74,0$ bilhões de UM). Entretanto, ele apresenta diferenças em relação ao bloco correspondente do atual SCN. Primeiramente, o consumo das familias e do governo é decomposto em consumo que resulta da poluição (tratamentos médicos, remédios, etc.), e em outro consumo A proposta para o sistema de contas satélites apenas separa esses dois tipos de "consumo"; ela não foi adiante, retirando do item consumo - que tem conotação de bem-estar - os gastos que as famílias e o governo fazem em decorrência da poluição.

Uma outra inovação é a inclusão no item "acumulação do patrimônio renovável", da variação da parcela do capital fixo que dá origem à produção de PCNs (a biomassa para a extração de produtos florestais; os rebanhos básicos para a produção pecuária etc., num total de 700 milhões de UM) O atual SCN não procede desta forma nem mesmo em relação aos rebanhos isso se traduz em aumento do $\mathrm{PIB}$, mas não há registro da redução que se verifica no patrimônio da economia. Entretanto, a revisão em curso do $\mathrm{SCN}$ deverá introduzir um tratamento adequado à questão, em linha com o feito no presente exemplo (Bartelmus, et al, 1989, p.12) $\mathrm{Na}$ Tabela 2, a soma do total do consumo intermediário (243,0 bilhões de UM) e do uso final ( 349,0 bilhões) é, evidente, igual ao valor da oferta total da economia (592,0 bilhões de UM). 
Tabela 2 - Uso de insumos, demanda final e valor adicionado ( $1{ }^{a}$ parte)

\begin{tabular}{|c|c|c|c|c|c|c|c|c|c|c|}
\hline & \multirow{3}{*}{ Oferta total } & \multicolumn{9}{|c|}{ Consumo Intermediário } \\
\hline & & \multicolumn{2}{|c|}{$\begin{array}{c}\text { Atividades } \\
\text { Económicas }\end{array}$} & \multicolumn{2}{|c|}{\begin{tabular}{c|} 
Serviços \\
governamentais
\end{tabular}} & \multicolumn{2}{|c|}{$\begin{array}{l}\text { Atividades Ambient } \\
\text { das familias }\end{array}$} & \multicolumn{3}{|c|}{$\begin{array}{r}\text { Todas as } \\
\text { atividades }\end{array}$} \\
\hline & & (a) & (b) & (a) & (b) & (a) & (c) & (a) & (b) & Total \\
\hline $\begin{array}{l}\text { Serviços de proteçāo } \\
\text { ambiental } \\
\text { Produtos de crescimento } \\
\text { natural } \\
\text { Outros bens e serviços } \\
\text { Total }\end{array}$ & $\begin{array}{r}36,2 \\
40,8 \\
515,0 \\
592,0\end{array}$ & $\begin{array}{l}31,4 \\
31,4\end{array}$ & $\begin{array}{r}22,5 \\
22,5 \\
131,1 \\
176,1 \\
\end{array}$ & $\begin{array}{l}2,4 \\
2,4\end{array}$ & $\begin{array}{r}5,0 \\
0,5 \\
13,7 \\
19,2 \\
\end{array}$ & $\begin{array}{r}8,7 \\
5,2 \\
13,9 \\
\end{array}$ & & $\begin{array}{r}8,7 \\
39,0 \\
47,7 \\
\end{array}$ & $\begin{array}{r}27,5 \\
23,0 \\
144,8 \\
195,3 \\
\end{array}$ & $\begin{array}{r}36,2 \\
\\
23,0 \\
183,8 \\
243,0 \\
\end{array}$ \\
\hline $\begin{array}{l}\text { Valor adicionado bruto } \\
\text { ajustado }\end{array}$ & & $(0,5)$ & 267,5 & 2,9 & 18,4 & $(13,9)$ & & $(11,5)$ & 285,9 & 274,4 \\
\hline $\begin{array}{l}\text { Custos ambientais } \\
\text { Depleçăo: reduçăo da } \\
\text { disponibilidade } \\
\text { Degradaçăo do meio- } \\
\text { ambiente } \\
\text { Transf. de recursos náo } \\
\text { renováveis do património } \\
\text { ambiental ao económico }\end{array}$ & & & $\begin{array}{r}39,5 \\
6,2 \\
33,3\end{array}$ & & $(3,3)$ & & 15,7 & & $\begin{array}{r}51,9 \\
6,2 \\
45,7\end{array}$ & $\begin{array}{r}51,9 \\
6,2 \\
45,7\end{array}$ \\
\hline $\begin{array}{l}\text { Produto Interno Bruto } \\
\text { Sustentável }\end{array}$ & & $(0,5)$ & 228,0 & 2,9 & 21,7 & $(13,9)$ & $(15,7)$ & $(11,5)$ & 234,0 & 222,5 \\
\hline $\begin{array}{l}\text { Consumo de Capital Fixo } \\
\text { Causado por condiçáo do } \\
\text { meio ambiente } \\
\text { Decorrente de outras } \\
\text { causas } \\
\text { Produto Interno Liquido } \\
\text { Sustentável }\end{array}$ & & $\begin{array}{c}3,1 \\
(3,6)\end{array}$ & $\begin{array}{r}23,2 \\
4,8 \\
18,4 \\
204,8 \\
\end{array}$ & 2,9 & 21,7 & $(13,9)$ & $(15,7)$ & $\begin{array}{r}3,1 \\
(14,6)\end{array}$ & $\begin{array}{r}23,2 \\
4,8 \\
18,4 \\
210,8\end{array}$ & $\begin{array}{r}26,3 \\
4,8 \\
21,5 \\
196,2\end{array}$ \\
\hline
\end{tabular}

Obs : (a) Proteçăo ambiental; (b) Outros, (c ) Degradaçăo Ambiental.

Tabela 2 - Uso de insumos, demanda final e valor adicionado (2. ${ }^{a}$ parte)

\begin{tabular}{|c|c|c|c|c|c|c|c|c|c|c|}
\hline & \multicolumn{10}{|c|}{ Demanda Final } \\
\hline & \multirow{3}{*}{$\begin{array}{l}\text { Expor- } \\
\text { taç̋̋s }\end{array}$} & \multirow{2}{*}{\multicolumn{2}{|c|}{$\begin{array}{c}\text { Consumo das } \\
\text { familias e do } \\
\text { governo }\end{array}$}} & \multicolumn{4}{|c|}{ Património econômico } & \multicolumn{2}{|c|}{ Património ambiental } & \multirow{3}{*}{$\begin{array}{c}\text { Total } \\
\text { da } \\
\text { De- } \\
\text { manda } \\
\text { final }\end{array}$} \\
\hline & & & & \multicolumn{2}{|c|}{ Renovável } & \multicolumn{2}{|c|}{ Năo renovável } & \multirow{2}{*}{$\begin{array}{l}\text { Transfer } \\
\text { p/ uso da } \\
\text { atividade } \\
\text { económica }\end{array}$} & \multirow{2}{*}{$\begin{array}{l}\text { Património } \\
\text { econ destr. } \\
\text { p/ causas } \\
\text { naturais } \\
\end{array}$} & \\
\hline & & (d) & (e) & $\begin{array}{l}\text { Capital } \\
\text { Fixo }\end{array}$ & Estoques & $\begin{array}{l}\text { Terral } \\
\text { Solo }\end{array}$ & Subsolo & & & \\
\hline $\begin{array}{l}\text { Serviços de proteçáo } \\
\text { ambiental } \\
\text { Produtos de crescimento } \\
\text { natural } \\
\text { Outros bens e serviços } \\
\text { Total }\end{array}$ & $\begin{array}{r}5,2 \\
68,8 \\
74,0 \\
\end{array}$ & $\begin{array}{l}35,0 \\
35,0\end{array}$ & $\begin{array}{r}11,2 \\
152,2 \\
163,4\end{array}$ & $\begin{array}{r}0,7 \\
68,6 \\
69,3\end{array}$ & $\begin{array}{l}0,7 \\
6,6 \\
7,3\end{array}$ & & & & & $\begin{array}{r}17,8 \\
331,2 \\
349,0 \\
\end{array}$ \\
\hline \multicolumn{11}{|l|}{$\begin{array}{l}\text { Valor adicionado bruto } \\
\text { ajustado }\end{array}$} \\
\hline $\begin{array}{l}\text { Custos ambientais } \\
\text { Depleçăo: reduçăo da } \\
\text { disponibilidade } \\
\text { Degradaçăo do meio- } \\
\text { ambiente } \\
\text { Transf. de recursos năo } \\
\text { renováveis do património } \\
\text { ambiental ao económico }\end{array}$ & & & & $\begin{array}{l}(25,3) \\
(25,3)\end{array}$ & & $\begin{array}{r}(27,9) \\
31,3 \\
\end{array}$ & $\begin{array}{l}26,5 \\
(4,9)\end{array}$ & $\begin{array}{r}(95,1) \\
(1,3) \\
(31,1) \\
(62,7) \\
\end{array}$ & $\begin{array}{l}38,6 \\
25,3 \\
13,3\end{array}$ & $\begin{array}{r}(51,9) \\
(6,2) \\
(45,7)\end{array}$ \\
\hline \multicolumn{11}{|l|}{$\begin{array}{l}\text { Produlo Interno Bruto } \\
\text { Sustentável }\end{array}$} \\
\hline $\begin{array}{l}\text { Consumo de Capital Fixo } \\
\text { Causado por condiçăo do } \\
\text { meio ambiente } \\
\text { Decorrente de outras } \\
\text { causas } \\
\text { Produto Interno Liquido } \\
\text { Sustentável }\end{array}$ & & & & $\begin{array}{r}(26,3) \\
(4,8) \\
(21,5)\end{array}$ & & & & & . & $\begin{array}{r}(26,3) \\
(4,8) \\
(21,5)\end{array}$ \\
\hline
\end{tabular}

Obs : (d) Resultado de poluiçăo, (e) Outros 


\subsection{Custos ambientais e o produto sustentável}

\subsection{1 $O$ valor adicionado bruto ajustado}

O valor adicionado bruto ajustado (ou PIB ajustado), no montante de 274,4 bilhões de UM, é obtido pela diferença entre a produção total menos as importações, e o consumo intermediário (243,0 bilhões). O PIB calculado com a metodologia do atual SCN seria igual a 293,3 bilhões de UM; a diferença está no uso de insumos pelas atividades de proteção ambiental dos setores de famílias e governo (13,9 bilhões e 5,0 bilhões de UM, respectivamente), que o atual SCN considera gastos de consumo e, portanto, uso final. O PIB ajustado satisfaz a igualdade:

Valor da produção $(517,4 \mathrm{~b}$ UM) - consumo intermediário $(234,0 \mathrm{~b})=$ Consumo ajustado $(198,4$ b) + Investimento (76,6 b) + Exportações (74 b) - Importações $(74,6$ b) $=274,4$ b UM

Note-se que, apenas com o deslocamento dos gastos das famílias e do governo em proteção ambiental para o consumo intermediário, o PIB ajustado já apresenta uma queda de quase $6,5 \%$ em relação ao PIB convencional. Como se verá adiante, o cômputo de elementos de custo ambiental provoca ainda outras reduções no valor desse indicador básico do sistema de contas nacionais.

\subsubsection{Os custos ambientais}

A forma de contabilizar os custos ambientais do país hipotético, no período de análise, pode ser vista na parte inferior da Tabela 2 . No sistema de contas satélites o registro dos custos ambientais vai além do cômputo dos impactos diretos das atividades de produção e de consumo. Inclui, também, os efeitos dessas atividades sobre o patrimônio tangivel da economia do qual, como vimos, fazem parte o patrimônio econômico e patrimônio ambiental.

Os custos ambientais resultam da depleção de recursos naturais e da degradação do meio ambiente. Por sua vez, esses custos podem se originar, tanto das atividades de produção e de consumo, como de fenômenos naturais

Como se pode ver na Tabela 2, os registros dos custos de depleção e de degradação são feitos com base no método das partidas dobradas. Assim, para cada registro de custo ambiental, há uma contrapartida de sinal contrário em alguma parte do bloco do patrimônio tangivel da economia. Observam-se, também, transferências entre os patrimônios ambiental e econômico e vice-versa, com as mesmas caracteristicas.

Seria ideal se houvessem levantamentos do patrimônio tangivel do país, tanto no início como no fim do período de análise. Se isto ocorresse, os registros das variações do patrimônio tangivel mostrariam as mudanças verificadas nos seus elementos ao longo do tempo. Ainda são grandes, entretanto, as dificuldades para a características exigidas pelo sistema de contas satélites ambientais. Mas este pode registrar as variações ocorridas no patrimônio tangivel. Segue-se um exame da determinação dos custos ambientais do pais hipotético da Tabela 2.

\section{Custos de depleção e transferências de recursos naturais}

i. No exemplo da Tabela 2, as atividades econômicas que provocam depleção de recursos naturais são:

- O setor agricultura, atividades florestais e pesca, num montante de 1,3 bilhões de UM, correspondente ao uso desregrado de recursos naturais de domínio público 
- a madeira extraida de florestas nativas, os estoques pesqueiros, água de fontes de suprimento sujeitas à depleção, ${ }^{3}$ etc. - além do permitido pela taxas de regeneração e recomposição desses recursos. Uma exploração que respeite essa regeneração não causa depleção, não originando, portanto, custos ambientais.

A contrapartida do valor da depleção verificada no periodo de análises aparece na coluna "transferências do patrimônio ambienta ao econômico" É como se as atividades econômicas retirassem recursos ambientais do meio-ambiente para destruí-ios

ii. O setor mineração, com a depleção do estoque de recursos minerais da economia No exemplo, a depleção do estoque de recursos minerais teve um custo de 4,9 bilhões de UM. Em contrapartida, houve redução, no mesmo valor, do patrimônio não renovável do subsolo.

iii. O patrimônio do solo e do subsolo da economia, embora não renovável e sujeito à depleção, pode ser ampliado mediante transferências (apropriações) da esfera ambiental onde tem status não produtivo. Isso ocorre com a incorporação de novas áreas à agropecuária em regiões de fronteira, e com a descoberta de novas reservas de recursos minerais.

No exemplo da Tabela 2 há uma adição de recursos da terra/solo de 31,3 bilhões de UM e uma contrapartida no mesmo montante, de redução do patrimônio ambiental, registrada na coluna "transferência do patrimônio ambiental ao econômico". E há uma aumento avaliado em 31,4 bilhões de UM do patrimônio do subsolo resultante da descoberta de novas reservas de petróleo e de outros minerais, e uma contrapartida no mesmo valor de redução do patrimônio do meioambiente. Como se pode ver na Tabela 2, as duas contrapartidas totalizam 62,7 bilhões de UM. Note-se que as transferências de recursos, do meio ambiente ao patrimônio tangivel da economia, não afetam os cálculos de produto e de uso final. Eles são registros de transferência patrimonial Só quando empregados na produção é que os novos recursos afetam àqueles cálculos

iv. O custo ambiental de desastre natural O exemplo faz a suposição de que, no período de análise, um terremoto causou fortes danos ao patrimônio econômico do pais hipotético - danos ou destruição de residências e prédios, de veículos, de equipamentos, etc Com isto, houve redução do capital fixo da economia no montante dos prejuizos mas de sinal positivo na coluna "transferência do patrimônio econômico ao ambiental". É como se o meio-ambiente (a natureza) retirasse da economia parte de seu patrimônio.

\section{Os custos de degradação}

No exemplo, os custos da degradação ambiental produzida pelo homem resultam, tanto das atividades de produção (33,3 bilhões de UM), como de ações do setor famílias (15,7 bilhões de UM) e do setor governo). como vimos, este último não só degrada o meio-ambiente, como efetua obras de regeneração. No exemplo, com suas atividades o governo gera custos de degradação ambiental de 2,0 bilhões de UM, mas desenvolve ações e obras de regeneração e proteção ambiental (limpeza de lagos, rios, recuperação de áreas erodidas etc.) no montante de 5,3

\footnotetext{
${ }^{3}$ A água é parte do patrimônio condicionalmente renovável da economia Quando usada de forma a permitir a manutenção dos fluxos desse recurso, não há custo de depleçäo (pode haver de degradação). Entretanto, se o uso ameaçar os fluxos desse recurso ciclico, haverá um custo de depleção, que deve ser registrado
} 
bilhões de UM; há pois um custo ambiental líquido, negativo, de 3,3 bilhões de UM (Tabela 2). Entretanto, a degradação ambiental não é apenas o resultado de atividades humanas. No exemplo, há duas categorias de degradação do meioambiente: a gerada pela ação do homem e que pode ser atribuída a setores específicos de atividade econômica, às famílias ou ao governo; e a degradação cuja autoria não pode ser claramente estabelecida, ou a causada pelo próprio meioambiente (a degradação do solo provocada por enchente, erosão natural, as emanações atmosféricas de vulcão, etc.).

Por seu turno, o exemplo distingue a degradação que atinge a terra, o solo, usado por setores de atividade, pelas famílias e pelo governo, da resultante da poluição (emissões atmosféricas, descarga de resíduos em rios, etc). Em seguida, examina-se o tratamento dado a esses tipos de degradação

i. A degradação da terra e do solo. A metodologia das contas satélites ambientais considera que, por seu caráter permanente, o solo está sujeito apenas a degradação ambiental (e não a uma depleção). No exemplo, as atividades econômicas de consumo, em conjunto, originam um custo de degradação do solo (agrícola e outros) avaliado em 14,6 bilhões de UM, e desastres e fenômenos naturais (principalmente uma enchente) geram custos de degradação de 13,3 bilhões de UM. Os custos ambientais da primeira categoria estão contabilizados no segmento intermediário (parte dos 33,3 bilhões de UM ali registrados); são custos que podem ser diretamente atribuídos aos setores que os provocaram. Os custos da segunda categoria (calamidades) estão registrados, com o sinal negativo, na interseção da linha degradação com a coluna patrimônio econômico não renovável terra/solo"; como os 14,6 bilhões de UM da degradação do solo, eles totalizam os 27,9 bilhões de UM ali contabilizados As contrapartidas, com os sinal contrário, estão registradas, no primeiro caso, na interseção da linha "degradação" com a de "patrimônio ambiental transferido a atividades econômicas"(parte dos $-31,1$ bilhões de UM ali contabilizados - o resto representa os custos da poluição); e, no segundo caso, na interseção da mesma linha com a coluna "patrimônio econômico destruído ou danificado por causas naturais)".

ii. A degradação causada pela poluição. Nos países industrializados, as atividades de produção e de consumo são os maiores fatores de degradação ambiental, atingindo a todas as esferas do meio-ambiente - o ar, a água, o solo, e a biosfera - , e afetando de várias maneiras os patrimônios econômico e ambiental. $\mathrm{O}$ impacto dessa degradação nem sempre pode ser adequadamente mensurado em termos monetários pois algumas vezes os seus efeitos não são inteiramente compreendidos, dificultando a avaliação econômica. Entretanto, boa parte é passível de avaliação econômica e esta é considerada pelo sistema de contas satélites ambientais

No exemplo a Tabela 2, a degradação ambiental por poluição gera um custo líquido atribuível às atividades de produção, de 18,7 bilhões, e às de consumo (atividades das famílias) de 15,7 bilhões de UM, que somados aos 14,6 bilhões do custo de regeneração da terra/solo e deduzidos os 3,3 bilhões dos gastos de regeneração do governo, totalizam os 45,7 bilhões de UM do custo líquido total de degradação A contrapartida dos custos de poluição, no mesmo calor pode ser vista na interseção da linha "degradação no meio ambiente" com a coluna "transferência do patrimônio ambiental à esfera econômica". Essa contrapartida representa a 
redução no valor do patrimônio ambiental causada pela poluição originária das atividades de produção e de consumo do país hipotético

\section{Os custos ambientais totais}

Como se pode ver na Tabela 2, no periodo de análise, os custos ambientais, tanto de depleção como de degradação, totalizam 51,9 bilhões de UM. Deste montante, 39,5 bilhões se originaram do processo produtivo e 17,5 bilhões das atividades do setor familias. O governo, por sua vez, produziu regeneração ambiental líquida, avalizada em 3,3 bilhões de UM. As contrapartidas desses custos tomaram a forma, de um lado, de reduções líquidas do capital fixo da economia (25,3 bilhões de UM) e no patrimônio ambiental (95,1 bilhões) e, do outro, de aumentos líquidos do patrimônio renovável do solo ( 3,4 bilhões de UM) e do subsolo (26,5 bilhões); e nas destruições do patrimônio econômico por causas naturais ( 38,6 bilhões de UM). Os elementos que produziram essas contrapartidas foram examinados acima.

\subsubsection{Os cálculos de produto sustentável}

\section{O PIB sustentável}

Das estimativas de valor adicionado bruto ajustado e de custos ambientais podese determinar o valor do Produto Interno Bruto Sustentável (PIBS), um importante indicador do sistema de contas satélites ambientais. No exemplo da Tabela 2, temos:

PIBS = Valor da produção (517,4 bilhões de UM) - Consumo intermediário ajustado (243,0 bilhões) - Custos Ambientais ( 51,9 bilhões) $=222,5$ bilhões de UM .

Este é o valor do produto bruto sustentável da economia no período de análise. Esse conceito de sustentabilidade apóia-se nos custos de depleção de recursos naturais, e nos custos necessários para evitar ou restaurar os danos ambientais ocorridos no período de análise (Bartelmus et al., 1989, p.22). No caso de depleção a regeneração é, via de regra, impossível, mas o sistema indica o investimento necessário para manter intacto no tempo o fluxo de renda

$\mathrm{Na}$ linha das identidades das contas nacionais, PIBS é igual à demanda final ajustada (a soma do consumo ajustado das famílias e do governo, com o acúmulo de capital fixo, a variação de estoques e as exportações, totalizando 349 bilhões de UM), menos as importações ( 74,6 bilhões e menos a soma algébrica do valor da destruição (uso final) de patrimônio econômico por causas naturais (-25 bilhões), do valor do incremento líquido do patrimônio não renovável do solo e do subsolo $(29,9$ bilhões) e do valor do patrimônio econômico retomado pelo meio-ambiente $(38,6$ bilhões); ou seja, menos 51,9 bilhões de UM. O resultado é de 222,5 bilhões

Um confronto dos indicadores da economia, obtidos pelo SCN tradicional e pelo sistema de contas satélites ambientais, revela que o PIBS é 18,9\% inferior ao valor adicionado ajustado (274,4 bilhões de UM), e $24,2 \%$ menor que o PIB convencional (293,4 bilhões de UM). O valor do produto é bem mais modesto quando se considera os custos ambientais da atividade econômica e os danos impostos pela própria natureza ao patrimônio econômico. Os dados de produtos obtidos sem tomar em conta os custos ambientais superestimam o produto bruto da economia e distorcem avaliações neles apoiadas, da evolução da economia do ponto de vista do desenvolvimento sustentável. Note-se finalmente, que uma Tabela 2 expandida permitiria a determinação do produto sustentável setorial, bem como o exame da 
contribuição para o produto das atividades de proteção ambiental, separadamente das demais atividades econômicas.

\section{O Produto Interno Líquido Sustentável}

Os dados da Tabela 2 permitem, também, calcular o valor do Produto Interno Líquido Sustentável do país do exemplo, no período de análise. Na parte inferior do bloco de consumo intermediário estão os dados de consumo de capital fixo - tanto aquele causado por condições do meio-ambiente $(4,8$ bilhões de UM), como o decorrente de outras causas (21,5 bilhões de UM) - num total de 26,3 bilhões de UM. Deduzindo-se esse montante do PIBS, chega-se a um PILS de 196,2 bilhöes.

A contrapartida do consumo de capital fixo, no mesmo valor, mas com sinal invertido, aparece na coluna de capital fixo da variação do patrimônio tangivel da economia. É interessante observar que, no período de análise a economia apresentou uma formação líquida de capital fixo de 17,7 bilhões de UM, ou de apenas $25,5 \%$ da formação bruta de capital fixo. Isso porque, além do desgaste de capital no processo produtivo (26,3 bilhões de UM), houve destruição de parte do patrimônio fixo por desastres naturais (25,3 bilhões de UM) O sistema de contas satélites ambientais permite, portanto, avaliação mais realista do estado da economia que a efetuada a partir de dados do SCN tradicional.

\section{VALORAÇÃO DOS CUSTOS AMBIENTAIS}

\subsection{0 problema}

A metodologia das contas satélites ambientais, em si, não apresenta grandes dificuldades, embora não possa ser considerada como produto acabado, permite a determinação de indicadores consistentes para análises da sustentabilidade do desenvolvimento de um país Isto desde que seja possivel equacionar satisfatoriamente um dos problemas fundamentais da metodologia, que até agora ficou à margem da discussão: o problema da valoração econômica dos impactos ambientais do processo de produção e de consumo, e dos gerados pela própria natureza (por catástrofes naturais). O exemplo acima apresentado considerou conhecidos esses custos, o que pode dar a idéia de que sua obtenção é trivial, evidentemente, isso não ocorre $\mathrm{O}$ estado das artes da valoração de impactos ambientais é uma colcha de retalhos de técnicas as mais variadas, algumas de validade indiscutivel, e outras controvertidas, mas que são empregadas por absoluta falta de melhores alternativas.

Os impactos ambientais que se pretende valorar são complexos. No caso da depleção dos recursos naturais as dificuldades são menores, mas os efeitos da degradação ambiental são qualitativos e freqüentemente não existem preços e valores monetários associados aos mesmos. Ademais, ocorrem interações entre diferentes formas de degradação ambiental, ainda não inteiramente compreendidas. Torna-se necessário o emprego de hipóteses, as vezes heróicas, para medir os custos desse tipo de impacto ambiental.

A macroeconomia convencional pouco tem a oferecer na questão da valoração dos impactos ambientais. Na mesma veia de Naredo (1987), Daly (1990, p. 19-21) mostra que a análise macroeconômica trata a economia como um subsistema isolado, fechado, que não interage com o sistema maior do qual faz parte $\dot{E}$ como se não houvesse trocas de matéria e energia entre o sistema econômico e o meioambiente, ou como se estas não tivessem importância. Com isso, a macroeconomia 
acaba ignorando os custos decorrentes de tais trocas. $\mathrm{Na}$ verdade, a tentativa de desenvolver um sistema de contas satélites pode vir a ser o passo inicial no estabelecimento das fundações de uma macroeconomia que considere as interações entre o sistema econômico e o meio-ambiente (Daly, 1990, p.27)

Se a análise agregada pouco tem a oferecer na questão da valoração de impactos ambientais, o contrário ocorre com a microeconomia e, particularmente, com a análise custo-beneficio Como em muitos casos os efeitos ambientais de ações no campo da produção e do consumo têm a natureza de externalidades, ${ }^{4}$ já há muito tratadas pela microeconomia, seus instrumentos vem sendo empregados no estabelecimento do valor de efeitos ambientais decorrentes da implantação de projetos especificos (ver Hufschmidt et al, 1983). Dada a complexidade e a extensão da matéria, um tratamento em profundidade da valoração dos custos da depleção e da degradação ambiental requer mais tempo e espaço do que os disponiveis nesta fase de nosso estudo. Assim, apresentamos apenas as linhas gerais das principais técnicas usadas com esse objetivo.

\subsection{Características das técnicas de valoração econômica de impactos ambientais}

Como vimos, no sistema de contas satélites, os custos ambientais resultam, de um lado, da depleção de recursos naturais e, do outro, da degradação ambiental, provocada principalmente por atividades de produção e consumo, mas também por catástrofes da própria natureza. Aspectos da valoração dessas duas categorias de custos ambientais são examinados a seguir

\subsubsection{Os custos de depleção}

Bartelmus et al, 1989, discutem apenas de passagem a determinação dos custos de depleção de recursos naturais. Em teoria, estes deveriam ser iguais ao montante de recursos financeiros necessários à realização de investimentos alternativos, que mantivessem intacto o fluxo de renda da economia. Embora correta conceitualmente, essa regra pouco nos diz sobre a maneira de determinar esses valores em casos concretos El Serafy (1990, p. 37-39) discute duas alternativas para tal a abordagem da depreciação e a abordagem do custo de oportunidade do uso do recurso natural (user cost).

Pela abordagem da depreciação; o patrimônio de recursos naturais seria tratado da mesma forma que o patrimônio construido pelo homem e que se desgasta no processo produtivo. Tomam-se dados físicos da depleção, ocorrida ao longo do período de análise, e aplicam-se preços de mercado correntes (quando disponíveis), para determinar o valor da "depreciação". Se a depleção é reversivel (no caso de recursos naturais renováveis) a valorização pode se basear no princípio do custo de recuperação ou restauração do recurso:

À primeira vista, este critério é lógico, mas ele apresenta problemas. Ao se empregar a abordagem da depreciação à valoração de recursos não renováveis, 0 produto bruto da economia não é afetado; entretanto, se deduz do produto líquido o valor integral desses recursos usados no periodo de análise. O PIB da economia

\footnotetext{
$4 \mathrm{Na}$ sua grande maioria, os custos de produção e de outras formas de degradação ambiental são externalidades por que tendem a não recair sobre os que os originaram Além disso, nem sempre é possivel computar inequivocamente tais custos, pois tendem a atingir de formas as mais diversas amplos segmentos da sociedade
} 
nada revelaria sobre depleção de recursos não renováveis e o produto líquido exageraria o "desgaste" do capital de recursos naturais. É como se a extração de recursos gerasse renda liquida.

A abordagem do custo de oportunidade ${ }^{5}$ equaciona esse problema decompondo o valor do recurso extraído e vendido num dado período no elemento de capital e no valor adicionado obtido a partir do processo de extração. O elemento capital é o valor descontado do custo de oportunidade de recurso não renovável; recebe ainda as denominações "renda" (rent) ou royalty [ver Cunha (1988), especialmente p.202]. Representa a verdadeira erosão do recurso, ou seja, o custo de sua depleção. Para El Serafy, esse valor deveria ser investido em formas alternativas de gerar renda, visando manter intacto no futuro o fluxo de renda da economia (ver Ward, 1982).

Com a alternativa do custo de oportunidade do uso, o custo da depleção afeta tanto o PIB como o produto líquido. O fator de depleção (o elemento de capital) é excluido do PIB sustentável, por sua vez, o componente de valor adicionado é mantido no produto líquido

Esse método está em harmonia com principios contábeis, uma vez que emprega na valoração preços de mercado, mas requer uma taxa de desconto arbitrariamente fixada para converter a parcela da receita das vendas associada ao elemento correto do significado económico de 'valor adicionado' e de 'renda' (El Serafy, 1990, p. 38).

A forma de decompor a receita líquida das vendas de um recurso natural não renovável em um dado período, $\mathrm{R}$, em custo de oportunidade descontado (user cost), Cd, e em renda, ou valor adicionado puro, $X$, pode ser vista em EL Serafy (1989). Ela se vale dos seguintes elemento as reservas do recurso, taxa corrente de extração do recurso; a expectativa de vida das reservas, medida em anos de extração à taxa corrente, e a taxa de desconto a ser aplicada $C d$, ou $(R-X)$, é o "fator de depleção", ou seja, o custo de depleção do recurso natural renovável. A metodologia é flexivel, permitindo tratar de fenómenos como mudanças na taxa de extração, a descoberta de novas reservas, alterações na taxa de desconto e extração do recurso em situação de perda de qualidade

O exemplo de Bartelmus et al. (1989) vale-se do método do custo de oportunidade do uso para determinar os custos de depleção dos recursos naturais renováveis da encomia no período de análise. Isso não é declarado no texto, mas a descrição dos cálculos ( $p$. 29) não deixa dúvida a respeito.

Apesar dos avanços da metodologia de cálculo do custo de depleção, ainda existem controvérsias e problemas nesta área Os principais têm a ver com a escolha da taxa de desconto a ser aplicada na determinação desses custos e com o tratamento a ser dado aos casos em que o preço do recurso não renovável apresenta fortes distorções. Como se viu, pelo método do custo de oportunidade do uso, a escolha da taxa de desconto afeta o cálculo do custo de depleção. Uma taxa elevada, deprimindo valor do recurso futuro, aumenta o componente $X$ (o valor adicionado); o contrário ocorre se forem usadas taxas reduzidas. Bartelmus et al. (1989, p.29) adotam uma taxa de $15 \%$ ao ano, bastante elevada, mas El Serafy (1990, p.39) sugere uma taxa de desconto bem mais modesta (5\%)

Existe controvérsia sobre se a taxa de desconto usada para estimar o valor do estoque de um recurso natural não renovável deve ou não ser tão elevada. $A$ questão é qual a pressão da taxa elevada sobre o meio-ambiente? A resposta

\footnotetext{
${ }^{5} \mathrm{O}$ custo de oportunidade do uso de recurso natural näo renovável pode ser visto como o valor que se pode obter no futuro, caso se adie hoje o consumo de uma unidade de recurso
} 
habitual é que, deslocando o capital e a mão-de-obra para empreendimentos que usem intensamente esse recurso, tal taxa aceleraria a depleção Este seria o efeito alocativo de uma taxa de desconto elevada e é com base nele que se costuma rejeitar o seu uso. Entretanto, conforme ressalta Daly (1990, p. 22), tende-se a ignorar o fato de que existem também um efeito escala. Ceteris paribus, uma taxa elevada reduz o número de empreendimentos que são viáveis. $\mathrm{E}$ a priori, nada se pode afirmar sobre qual desse dois efeitos predominaria. Se, em caso concreto, predominar o efeito escala, seria recomendável usar taxa de desconto maior

Pode-se alegar que a taxa de desconto é empregada apenas para fins contábeis. Entretanto, esse argumento não é válido caso se adote a regra de investir em outras áreas da economia o equivalente ao custo de depleção do recurso, visando garantir renda sustentável no tempo. Nesse caso, uma taxa elevada tornaria mais difícil encontrar alternativas de investimento viáveis para a aplicação de tais recursos. Outro problema é o de como tratar os ganhos de capital na valoração da depleção. A regra do custo de oportunidade do uso, como enunciado por El Serafy (1990), manda tomar o preço de mercado. Implícita está a hipótese de que este não apresenta fortes distorções; mas, e se o contrário for verdadeiro? No final da década de 1970, por exemplo, a atuação do cartel da OPEP fez o preço do petróleo atingir níveis bastante superiores aos de "mercado livre"; tanto é que, recentemente, com a perda de poder do cartel, esses preços caíram significativamente a ponto de nem a Guerra do Golfo ter possibilitado recuperação significativa. O que fazer nos casos em que, em um dado período de tempo, o preço de mercado de recurso não renovável incluir forte adicional de monopólio? $E$, se por algum motivo houver um dumping? Essas são questões ainda não tratadas adequadamente.

\subsubsection{Os custos de degradação ambiental}

Na Tabela 2, a degradação ambiental foi responsável por cerca de $88 \%$ do custo ambiental total. Trata-se de exemplo hipotético, mas construido com base em suposições realistas, essa proporção dá, portanto, uma idéia da importância relativa desse tipo de custos.

Em linhas gerais, a regra que orientou os autores do exemplo na valoração da degradação ambiental, e que se coaduna com o conceito de sustentabilidade, é a da "estimativa dos custos que seriam necessários para evitar" a degradação, restaurar ou substituir os elementos degradados do meio-ambiente "no período de referência". Ou seja, o custo da degradação é representado pelo "montante de dinheiro necessário para manter intacto o meio-ambiente" (Bartelmus et al.,1989, p.22). Há critério de valoração alternativo, desenvolvido com base na teoria do bem-estar, que consiste na estimativa de nivel econômico ótimo de degradação. Este seria determinado igualando o custo marginal de medidas de prevenção e proteção contra a degradação, com o somatório do fluxo descontado dos danos ambientais no futuro, em caso de näo adoção de tais medidas. Os custos ambientais seriam definidos a partir das atividades de proteção (reais ou virtuais) estabelecida segundo essa regra (Bartelmus et al ,1989, p. 22).

Antes de mais nada, este é um critério de difícil operacionalização. Como determinar com um mínimo de exatidão os danos ambientais futuros relacionados com diferentes niveis de degradação? 
Mas mesmo que existissem informações adequadas a respeito, a regra tenderia a produzir subestimações dos custos da degradação ambiental. O ponto-chave está na taxa de desconto do fluxo futuro de danos causados por um meio-ambiente em deterioração, é de se esperar que esta seja elevada. Com efeito, só não haveria um desconto elevado dos custos ambientais das gerações futuras se os indivíduos que compõem a geração presente estivessem adequadamente "educados" a respeito do que significaria para as gerações futuras uma deterioração ambiental crescente, se dispusessem de todas as informações necessárias para avaliar isso corretamente; e se tivessem forte propensão ao altruísmo. Como é quase utópica a conjunção de todas essas condições, o emprego do critério tenderia a gerar subavaliação de custos ambientais

Pode-se alegar que bastaria usar taxas de desconto reduzidas nos cálculos para eliminar a subavaliação. Entretanto, procedendo dessa forma, estariamos injetado um elemento de arbitrariedade, que contraria a própria natureza do critério. Os proponentes deste justificam o seu emprego com o argumento de que, com ele, são obtidas soluções que refletem as preferências dos indivíduos em sociedade, e não a opinião de tecnocratas ou burocratas. Se couber a estes estabelecer a taxa de desconto a ser usada na aplicação do critério - argumentam - é preferível procurar alternativas mais simples para medir o custo ambiental, pois o critério cessaria de refletir as preferências dos indivíduos em sociedade.

Acontece, entretanto, que a regra apoiada na teoria do bem-estar reflete as preferências dos individuos da geração presente. As das gerações futuras não podem ser determinadas. Ademais, causa espécie a cientistas e técnicos da área ambiental o fato de que a aplicação do critério gere solução admitindo alguma deterioração ambiental (a deterioração "ótima"), especialmente porque esta pode não se coadunar com a meta do desenvolvimento sustentado

A valoração pelos custos também tem base teórica, o critério-padrão de Pareto, aplicado a problemas de alocação intertemporal. Por este, a valoração seria obtida pela quantificação dos danos às gerações futuras, da deterioração ambiental causada no presente Essa quantificação corresponderia à variação compensada ou equivalente da deterioração. Tratar-se-ia da variação do patrimônio (real ou virtual) dos indivíduos das gerações futuras, necessárias para compensá-los pela deterioração (variação compensada), ou essa variação de patrimônio num montante equivalente às perdas produzidas pela geração ambiental no presente (variação equivaiente) ${ }^{6} \mathrm{Na}$ aplicação da abordagem da valoração pelos custos, entretanto, o hiato entre a teoria e a prática é grande. Seria muito difícil operacionalizar a aplicação da teoria em seus termos exatos.

A despeito desse problema e do grau de arbitrariedade que envolve, por ser de mais fácil aplicação, prevaleceu, na nova metodologia de contas satélites ambientais, a regra do custo de manter intacto o meio-ambiente. Mesmo assim, a regra apresenta complexidades, dada a variedade de situações a serem consideradas. A degradação ambiental engloba impactos dos mais diferentes tipos e origens, grande parte dos quais difíceis de quantificar e transformar em valores monetários Ademais, para parcela considerável dos casos, não é fácil ligar com exatidão os danos ambientais aos responsáveis por eles (por exemplo, os efeitos sobre a saúde da poluição do ar), o que torna complicado atribuir, no bojo do SNC

\footnotetext{
${ }^{6}$ Os conceitos de variação compensada e de variação equivalente säo semelhantes, ver Maler (1990)
} 
reformulado, os custos de degradação aos setores que a causaram.

Quando a degradação tem reflexos nítidos sobre o processo produtivo, ou sobre - patrimônio físico da economia, é mais fácil medir o custo a ela associado. A situação se complica nos casos da valoração das degradação de outros tipos. Técnicas vêm sendo desenvolvidas, mas há muito ainda a ser feito nesse campo (ver Hufschmidt et al, 1983, especialmente caps 3, 6 e 7, Dixon, 1990) A seguir, é tratada a valoração da degradação ambiental, que afeta mais diretamente o sistema produtivo ou o patrimônio físico da sociedade, e são indicados os principais caminhos para a valoração dos outros tipos de degradação.

\section{i. Efeitos ambientais que afetam o sistema produtivo e o patrimônio.}

Algurns tipos de degradação ambiental atingem diretamente os recursos produtivos, provocando quedas de produtividade. Quando isso acontece, os custos de degradação podem ser estimados pela redução, em valor, da produção por ela causada. Formas de degradação fazem com que ocorram quedas de rendimento físico da agricultura (pela erosão ou pela perda de fertilidade do solo, por exemplo), da atividade florestal (pela chuva ácida, por exemplo), da captura de peixes (pela poluição das águas, por exemplo), na produção hidroelétrica (por sedimentação de reservatórios, por exemplo), entre outras. Essas quedas de rendimento são mensuráveis e há preços de mercado para os produtos dessas atividades. A valoração não oferece, portanto, grandes dificuldades.

Uma forma alternativa de valorar os efeitos de deterioração ambiental sobre um dado recurso produtivo consiste na determinação dos gastos, reais ou virtuais, necessários para corrigir a deterioração. Nesta linha, é possivel determinar, também o valor da deterioração causada por condições do meio-ambiente a edifícios, casas, pontes e outras estruturas fisicas. A situação se complica, entretanto, se uma dada estrutura possuir valor histórico ou artístico inestimável Uma solução aproximada é a de considerar custo ambiental o dispêndio (real ou virtual) necessário para restaurar e manter em boas condições tais estruturas

Questão mais delicada é a da valoração dos impactos da poluição, diretamente sobre o homem como agente produtivo. Alguns tratam-na sem maiores reservas. "Seres humanos também podem ser considerados recursos produtivos. Quando os danos da degradação do meio-ambiente se fazem sentir sobre a saude humana, a valoração torna-se mais dificil, mas existem vários métodos para tal, inclusive o de estimar as perdas econômicas devidas ao declínio da produtividade dos trabalhadores, decorrentes de danos à saúde ou por morte prematura" (Hufschimdt et al., 1983, p.59). É possivel antever, entretanto, as obsessões éticas, notadamente em face a tentativas de atribuir valor monetário à vida humana para uso no novo SCN

\section{ii. Os custos dos outros tipos de degradação ambiental}

Em muitos casos, o efeito da degradação faz-se sentir, não tanto em termos de quedas de produção ou de perdas patrimoniais, mas sim de danos a função de recreação e lazer ou estéticas do meio-ambiente, bem como à própria capacidade deste de oferecer condições de vida aceitáveis. Nesses casos, usualmente está envolvida uma categoria de bens amplamente consumidos sem que os individuos tenham, necessariamente, de pagar por esse consumo - os bens públicos. Muitas vezes as atividades de produção e de consumo causam a degradação desse tipo de 
bens. Como exemplos, podem-se citar: a destruição das Sete Quedas quando da formação da represa de Itaipú; a deterioração de monumento artístico por chuva ácida, a degradação da qualidade do ar em centro urbano.

Não existem preços de mercado adequados para orientar a valoração deste tipo de danos ambientais, as a teoria dos bens públicos com o conceito de "disposição de pagar". (willingness-to-pay), vem servindo de base para a realização de estimativas das perdas dos consumidores nesses casos. Um bem público puro é aquele disponivel para o consumo de todos sem custo. $\mathrm{O}$ consumo é coletivo e não pode haver exclusão; ou seja, o consumo de um indivíduo é coletivo não preclude o dos demais. É impossivel ou extremamente dispendioso fazer com que alguém seja excluído do consumo por se recusar a pagar (ver Mueller, 1972). Tipicamente tais bens são gratuitos (exemplo seria um belo por do sol) ou se cobram preços pelo acesso ao consumo que não tem relação com o bem-estar que ocasionam aos consumidores (a cobrança de ingresso a um parque nacional).

Como freqüentemente bens e serviços ambientais são bens públicos, não há preços de mercado adequados para valorar a degradação que os atinge. Para esses casos, vem sendo desenvolvidas e aperfeiçoadas técnicas, geralmente apoiadas em inquéritos e levantamentos amostrais, objetivando a valoração indireta das demandas implícitas por tais bens e serviços. Tentando estabelecer, mesmo que de forma aproximada, a "preferência revelada" dos indivíduos por esses tipos de bens, essas técnicas se propõem a determinar a disposição destes de pagar por serviços ambientais, servindo de base, assim, para valoração de sua degradação (ver Hufschimdt et al., 1983, cap 6, e Pearce, 1978).

Essas técnicas estão sujeitas a duas linhas de críticas: críticas ao pressuposto de que os indivíduos são os melhores juizes a respeito do valor de uma dada degradação ambiental; e as criticas aos problemas que a distribuição de renda traz à valoração com tais técnicas. A primeira dessas linhas põe em dúvida a suposição, implícita nas técnicas de medição indireta, de que os indivíduos realmente desejam, e sempre são capazes de fazer julgamentos sobre o valor dos serviços ambientais. Há dúvidas sobre se os indivíduos estão em condições de avaliar em profundidade os impactos de mudanças ambientais sobre o seu bem-estar, via de regra esses impactos são complexos, ocorrem de forma não claramente visivel e se misturam a efeitos de outros tipos.

As críticas apoiadas nos efeitos da distribuição de renda sobre a valoração é mais ampla, pois pode se estender também a valoração apoiada em preços de mercado (ver adiante). Essa linha de crítica chama a atenção para o fato de que a distribuição de renda afeta severamente as avaliações baseadas na habilidade de pagar Supondo-se que se contornem os problemas técnicos para a sua aplicação, essas técnicas captam, são só o que os individuos estariam dispostos a pagar para evitar degradação, mas também a habilidade de realizar tais pagamentos. Entretanto, se a renda é muito mal distribuída, essa técnicas acabariam captando as preferências dos grupos de renda elevada. A massa dos pobres poderia ter fortes preferências por certos serviços ambientais mas, com sua habilidade de pagar é reduzida, a metodologia acabaria por não registrar adequadamente esse fato. Como indicam Hufschimdt et al. (1983, p. 63), as perdas de bem-estar causadas pela poluição, que produz deterioração da saúde de amplos segmentos da sociedade, 
podem não ser corretamente mensuradas se depender de metodologias de disposição de pagar.

\section{iii. O uso do critério do custo-eficácia}

Os problemas e dificuldades relacionados ao emprego de critérios de avaliação dos custos ambientais que, de alguma maneira, reflitam as preferências dos individuos em sociedade, levaram a sugestōes da substituição destes por critério apoiado na análise do custo-eficácia. Após exprimir seu ceticismo em relação a validade das metodologias de disposição a pagar, Hueting (1989), por exemplo, sugere que, ao invés, se estabeleçam corn base em considerações de sustentabilidade do desenvolvimento ou sobre a saúde da população, metas e padrōes e que se determine os dispêndios necessários para os atingir, da forma mais eficaz possível. A magnitude desses dispêndios (atuais ou virtuais) representaria o custo da deterioração ambiental.

A sugestão de estabelecer, com o apoio em critérios técnicos e científicos, metas de qualidade ambiental para servir de base, entre outras coisas, à determinação dos custos da degradação ambiental, vale-se do argumento de que os efeitos da mudança ambiental são pouco entendidos pelo público, ou que atingem significativamente às parcelas mais pobres da população, cujas preferências não são captadas pelos critérios baseados na preferência individual expressa em mercados. Assim, caberia a organizações governamentais especializadas fixar tais metas; uma vez feito isto, seria também uma questão técnica determinar as ações e medidas necessárias para o atingimento dessas metas, estabelecer custos e escolher as mais eficazes.

As objeções a respeito do elevado grau de arbitrariedade desse critério são respondidas apontando para as dificuldades com os outros e para o fato de que, em sociedade democrática, existem meios de evitar com que as metas ambientais percam sintonia com os interesses da maioria da população

Pode ser muito dificil determinar os valores dos individuos em sociedade, mas os formuladores de políticas se sentem em solo firme ao supor que melhorias de saúde e prevenção de danos ambientais sérios têm prioridade elevada na avaliação da maioria das pessoas, inclusive as de baixa renda (Hufschimdt et al., 1983, p. 62).

\subsection{Preços, valoração e distorções - significados e problemas}

$\mathrm{Na}$ determinação dos custos ambientais, tanto no âmbito da análise custobenefício de impactos ambientais de projetos, como pelo novo sistema de contas satélites ambientais, há procura ávida de preços de mercado ou, na sua ausência, de preços-sombra ou preços sintéticos, para uso na valoração de tais impactos. No estabelecimento do valor dos impactos ambientais, esses preços têm duas funções básicas uma, a mais óbvia, é a de tornar possivel a adição de coisas diferentes Por melhor que seja a disponibilidade de informações físicas a respeito de diferentes impactos ambientais de atividades econômicas, sem preços é impossível agregá-los de modo a originar um valor monetário global desses impactos (os custos), para uso no sistema de contas satélites

A outra função dos preços - menos ressaltada - é a de servir de ponderação aos vários componentes dos impactos ambientais É por essa razão que, para as aplicações, não servem quaisquer preços; é frequente, nos textos que tratam do assunto, a recomendação do emprego apenas de preços que não apresentem 
distorções. Isso é feito porque estes têm um significado especial - o de transmitir o peso que a sociedade atribui a cada componente dos impactos Entretanto, observa-se a tendência a ignorar-se o significado exato do uso de preços na valoração de custos ambientais.

A origem de preocupação com o uso de preços "adequados" está na teoria do bem-estar social, subjacente às tentativas de valoração Para essa teoria, dentro de certas hipóteses, o livre funcionamento dos mercados conduziria a economia a uma configuração de equilíbrio de ótimo de bem-estar social Numa situação destas, entre outras coisas, os preços de bens e serviços seriam iguais aos respectivos custos marginais das empresas maximizadoras, e estes, aos custos marginais sociais, bem como aos beneficios marginais sociais. Atingidas as condições marginais de equilibrio, a sociedade estaria num ótimo de bem-estar. no sentido de que não seria possivel rearranjar a situação para melhorar o bem-estar de qualquer individuo sem sacrificar o de pelo menos um outro (ver Bator, 1957).

O paradigma da teoria do bem-estar é substrato teórico - geralmente implícito de várias aplicações. Com base nele, por exemplo, mede-se o custo social de distorções que impedem a livre formação de preços em mercados, ou os ganhos sociais da remoção de obstáculos desse tipo Semelhantemente, a teoria está implícita no emprego que a análise custo-benefício convencional faz de preços líquidos de projetos avaliados.

Como vimos, a valoração dos custos ambientais para o sistema de contas satélites, faz amplo emprego das técnicas usadas pela análise custo-benefício aplicada à avaliação de impactos ambientais (positivos ou negativos) de projetos Observa-se, também, a ênfase na procura de preços de mercado não "distorcidos" para uso na valoração; e, quando não disponiveis, tentam-se desenvolver técnicas para estimar preços sombra ou preços sintéticos

Ao proceder desta forma, está-se, no fundo, extrapolando aspectos da teoria do bem-estar, válida sob condições muito especiais, para casos concretos em que essas condições longe estão de se verificar. Estas - as hipóteses básicas da teoria do bem-estar - são todos os mercados devem ser perfeitamente competitivos; não podem existir externalidades de nenhum tipo, as políticas públicas não introduzem distorções, e, como a análise é estática, elementos como crescimento econômico e mudança tecnológica são afastadas das hipóteses

É quase desnecessário mencionar que nenhuma economia real se conforma a tais condições. Perde, portanto, muito de sua legitimidade teórica, a utilização de preços de mercado, não "distorcidos", para aproximar situação de ótimo - ou seja, uma configuração na fronteira de possibilidade de utilidade da economia Ademais, usam-se preços não distorcidos em aplicações isoladas como se, apenas com isto, a economia estivesse se aproximando, mesmo que minimamente, de uma situação de ótimo. $\dot{E}$ como se, ao remover parcialmente distorções, a economia automaticamente se movesse no sentido da fronteira. Entrelanto, segundo nos revela a teoria do bem-estar, quando as distorções são muitas (o que tende a ocorrer no mundo real), nada nos garante que, eliminando apenas uma delas, haverá melhoria de bem-estar social. Pode até se dar o contrário

Há um outro problema ainda mais sério com o uso de preços de mercado na valoração Mesmo que, por circunstâncias extraordinárias, a economia estivesse, em um dado momento, numa configuração de ótimo, é preciso lembrar que a 
fronteira de possibilidade de utilidade admite um número infinito de configurações destas (de pontos de ótimo limitado), cada uma com um conjunto de preços relativos de equilibrio A questão é será que basta atingir a fronteira? Novamente, a teoria do bem-estar nos mostra que, se admitirmos julgamentos de valor, pode ser que pontos internos à fronteira sejam "melhores" do que certos pontos na fronteira Se um ponto de ótimo significar enorme bem-estar para um grupo reduzido da sociedade, em detrimento da maioria, sob certo prisma - e aqui entram juigamentos de valor - seria válido atuar para aumentar o bem-estar dessa maioria às custas do grupo reduzido, mesmo que, com isto, a configuração se movesse para dentro da fronteira Novamente, a mera eliminação de distorções não significa que se atingirá situação "melhor" do que a anterior

Esse tipo de raciocínio está atrás de uma das obsessões de Norgaard às tentativas de reforma do Sistema de Contas Nacionais para nele incluir a dimensão ambiental. Como vimos na seção 1 , esse autor objeta quanto à relevância de valorações feitas com base em preços que refletem "as instituições sociais vigentes que definem a posse de riqueza e poder econômico e facilitam certas atividades e tecnologias e restringem outras" (Norgaard, 1985)

As observações desta subseção não se destinam a diminuir a importância das tentativas em curso de aprimorar o SCN com a inclusão da dimensão ambiental nas contas nacionais. Elas objetivam apenas colocar as coisas nas suas devidas proporções; se isso ocorrer, o SCN aperfeiçoado será desenvolvido para se tornar apenas uma peça, embora importante, de um sistema amplo de informações e indicadores para a avaliação da sustentabilidade do desenvolvimento de economias em situações concretas, e não o elemento predominante

\section{BIBLIOGRAFIA}

AHMMAD, Y, EL SERAFY, S. e LUTZ, E. Environmental accouting for sustainable development. Washington World Bank, 1989

BARTELMUS, P. CARSTEN, S. e VAN TONGEREN, J. SNA framework for integrated environmental and economic accouting. Trabalho apresentado à $25^{\text {a }}$ conferência geral da International Association for Research in Income an Wealth Lahnstein, Alemanha Ocidental, 20 a 25 de agosto de 1989,40 p. e apêndices.

BATOR, F. M The anatomy of market failure. Quarterly Journal Economics, v. 72, p. 351-79, 1958

CEPAL/PNUMA Informe del seminário regional sobre invetarios e cuentas del patrimonio natural y cultural avances y perspectivas an America Latina y el Caribe Santiago CEPALPNUMA, 26-28 de mar., 1990.

WORLD COMMISION ON ENVIRONMENT AND DEVELOPMENT. Our common future Oxford Oxford University Press, 1987

CUNHA, A S. Economia dos recursos naturais o caso do desamamento da Amazônia. In BRANDÃO, A S

$P$ Os principais problemas da agricultura brasileira Rio de Janeiro: IPEA/PNPE, 1988, p. $181-242$

DALY, H. Towards an environmental macroeconomics. Revista de Analisis Económico, v.5, n 2, p 19-31, nov. 1990.

DIXON, J A Applying economic analysis to enviroment problems opportunities and constraints Revista de Analisis Económico, v.5, n. 2, p 45-60, nov 1990.

EL SERAFY, S. National resoursce accountig an overtiew Trabalho apresentado no simpósio the environment and economic research Londres Regent's College, ODI, mar., 1990

EL SERAFY, S e LUTZ, E. Towardas improved accouting for natural resources and the enviroment Revista de Analisis Económico. v. 5, n. 2, nov. 1990

HUFSCHMIDT, M M, JAMES. D., MEISTER, A. D. BOWER, B.T e DIXON, J A Environement, natural systems, and development - an economic valuation guide. Baltimore/London The Johns Hophins university Press, 1983

MALER, K G. Economic theory and environmental degradation a survey of some problems. Revista de Analisis Económico, v. 5, n 2, p 7-17, nov 1990

MEADONWS, D L RANDERS, J e BEHRENS III. W W The limits to growth Nova Yorque: Universe 
Books, 1972.

MUELLER, C C A teoria dos bens públicos e a economia do bem-estar Revista IPE - Instituto de Pesquisas Económicas, v. 2, n. 4, p 95-112, 1972

MUELLER, C C S Situaçăo a da produção de informação sobre o meio-ambiente Ciência da Informação. Brasilia, v. 21, n. 1, jan /abr, p. 14-22, 1992.

NAREDO, J.M. Qué pueden hacer los economistas para ocuparse de los recursos naturales? Desde el sistema económico hacia a la economia de los sistemas. Pensamiento lberoamericano, n. 12, jul./dez. 1987.

NORGAARD, R B., Three dilemas of environmental accounting Versão prelim. Univ of California, Berkeley, 1985

PEARCE, D. W (org) The valuation of sacial costs. Londres: Allen and Unwin, 1978

TSAKOUMAGKOS, P Indicadores econômico - ambientales para las cuentas nacionales Seminario regional sobre inventarios e cuentas del patrimonio natural y cultural - avances y perspectivas an America Latina y el Caribe. Santiago, Chile, 26/28 de março, 1990, $90 \mathrm{pp}$

UNITED NATIONS. Report of the United Nations conference on the human enviroment - Stockolm, June 516, 1972 Nova Yorque Naçöes Unidas, 1973

WALSCHBURGER, A C EI Estado del arte en metodologias de cuentas de patrimonio natural Seminario regional sobre invetarios e cuentas del patrimonio natural y cultural - avances y perspectivas an America Latina y el Caribe Santiago, Chile, 26/28 de março, 1990, 42 pp

WARD, M. Accouting for the depletion of natural resources in the national accounts of dev. economies Paris: OECD, 1982

\section{ABSTRACT \\ THE NATIONAL ACCOUNT \\ THE ENVIRONMENTAL COSTS OF THE ECONOMIC ACTIVITY}

The growing concern with the environmental impacts of economic activities in modern societies has had repercurssions on the field of statistics. Its was realized that the national accounts - the synthesis system of the aggregate economy - is totally incapable of measuring such impacts Activities that generate strong environmental degradetion are often registred as providing positive contribuitions to the economy, and an expansion originated in the depletion of an exhaustible resorce is accounted as growth - producing Such problems gave rise to an effort, led by the United Nations and the World Bank, to reform the system, making it able to correctly register the economic impacts of the environmental degration stemming from production and consumption activies. The object of this article is to evaluate the main problems with the present national accounts system, and divulge a proposal, currently being tested, for the implementation of a system of satellite accounts that would allow the national accounts system to get around such probiems. 